\section{Diabetic retinopathy: some cellular, molecular and therapeutic considerations}

\section{Introduction}

Any young ophthalmologist wishing to explore the scientific basis of ophthalmic disease could not adopt a better role model than William Bowman, who arguably was our most remarkable and pre-eminent clinician-scientist. In 1832 , at the early age of 16 years, Bowman served as apprentice to the Birmingham surgeon Hodgson, with whom he developed his exceptional observational and recording skills.

Later, as an anatomy demonstrator and medical student at King's College, London, he demonstrated his huge capacity for assembling, cataloguing and organising data, leading to the compilation of a comprehensive work on the anatomy and physiology of the body, a standard text at the time. ${ }^{1,2}$

Before long Bowman's insatiable appetite for discovery, coupled with the serendipitous acquisition of a new compound microscope, led him to explore the microanatomy of numerous human and vertebrate tissues and organs and indulge his passion for the meticulous and exact recording of his findings, often in breathtaking detail, given his tools at the time. He made many clinico-pathological correlations in diverse disease processes and elegantly documented, for the first time, structures in the eye and kidney which bear his name to this day.

Bowman's ordered and disciplined approach to the analysis and documentation of his anatomical and pathological discoveries was matched only by a raft of innovations relating to the preservation and fixation of histological specimens which allowed him to survey the delicate and intricate tissues of the eye in unprecedented detail. He used the 'glycational' properties of syrup to stabilise and fixate the friable and unwieldy retina long before standard cross-linking techniques evolved and exploited agitational micro-dissection methods to separate the retinal microvascular from neural tissue more than a century in advance of trypsin digestion methods. ${ }^{2}$
Bowman made no direct contribution to the understanding of the pathology or pathogenesis of diabetes mellitus as the link between pancreatic islet cell loss and glycosuria was only established by Minkowski in 1889, some 50 years after Bowman's principal discoveries. ${ }^{3}$ Nevertheless, Bowman's incisive anatomical studies on three of the prime targets for diabetes, i.e. basement membranes, muscle cells and the renal glomerulus, provided a firm histological platform for future pathological studies.

It has been known for at least 120 years that diabetes mellitus has a deleterious effect on the retinal circulation, and reports dating to the last century clearly depict the characteristic and often inexorable retinopathy that afflicted patients with severe, uncontrolled and longstanding disease. ${ }^{4,5}$ The discovery of insulin in 1923 dramatically improved the survival of insulin-dependent diabetics but increased the length of time the retinal vasculature was exposed to conditions of variable glycaemia, and diabetic retinopathy was ultimately found to affect most insulin-dependent and noninsulin-dependent diabetics who survived the condition for 20 years or longer. ${ }^{6,7}$ Despite advances in medical and surgical management, diabetic retinopathy remains the commonest cause of registrable blindness in young and working adults in the United Kingdom and most industrialised countries. ${ }^{8}$

Because of its visibility and ready access to photography the retinal vasculature has been the most scrutinised microcirculation in the body and in the 1960s angiographic techniques were developed which could resolve capillaries measuring only 5-10 $\mu \mathrm{m}$ in diameter. Since then diabetic retinopathy has been documented in exquisite detail, revealing characteristic vessel calibre changes, microaneurysms, perfusion defects and intra- and preretinal neovascularisation in the affected microvasculature. Fluorescein angiography has provided a sensitive measurement of vascular
Desmond B. Archer Department of Ophthalmology Eye \& Ear Clinic Royal Victoria Hospital Grosvenor Road Belfast Northern Ireland BT12 6BA, UK e-mail: d.archer@qub.ac.uk 
competence and in parallel with other ingenious techniques such as laser Doppler interferometry and blue entopic field measurements, demonstrated a range of haemodynamic alterations during the course of the disease process.

In vivo structural and functional analyses of the human diabetic retinal microvasculature were paralleled by histopathological investigations which exploited the regular architecture of the retinal vessels and their resistance to trypsin digestion. Basement membrane thickening and pericyte loss were established as the histological hallmarks of early diabetic retinopathy and vascular occlusion, with varying degrees of channel repair and extraretinal vasoproliferation, was recognised as the key feature of more advanced retinopathy. Animal models of diabetic retinopathy, although not fully reproducing the human vasculopathy, helped unravel some of the early dynamic and histopathological changes induced by a hyperglycaemic microenvironment. Cell culture studies facilitated analysis of retinal microvascular pericytes and endothelial cells in isolation and in co-cultures, adding to our knowledge of the unique molecular and biochemical properties of these cells and their responses to high glucose concentrations. The application of ultrastructural, biochemical and molecular biological investigative methods to the retinal circulation have also clarified how vascular and paravascular cell processes alter in diabetes. Such studies have highlighted conditions under which such cells can become progressively dysfunctional and suggested strategic points in the disease process where corrective or supportive therapies might be instituted.

There have been few therapeutic innovations to prevent or significantly ameliorate diabetic retinopathy, and at present emphasis is on achieving neareuglycaemia and avoiding or modulating known risk factors, such as smoking, uncontrolled hypertension, hyperlipidaemia and anaemia. ${ }^{9,10}$ Treatment for established and sight-threatening diabetic retinopathy is largely by laser photocoagulation. This technique has proven value in certain forms of diabetic retinopathy, but is inherently destructive and has its own retinue of complications, particularly loss of colour vision, contrast sensitivity and visual field. Vitreous haemorrhage and fibrovascular membranes which threaten the macula can be removed by vitrectomy procedures and serviceable vision salvaged; however, many such patients already have ischaemic retinae where the disease process has largely run its natural course and visual recovery may be disappointing.

It is now clear that any treatment to preserve full vision in diabetes must be instituted before capillary instability, incompetence and closure occur. This requires a more sophisticated understanding of the inner blood-retinal barrier and the response of its component cells to sustained hyperglycaemia. This paper outlines

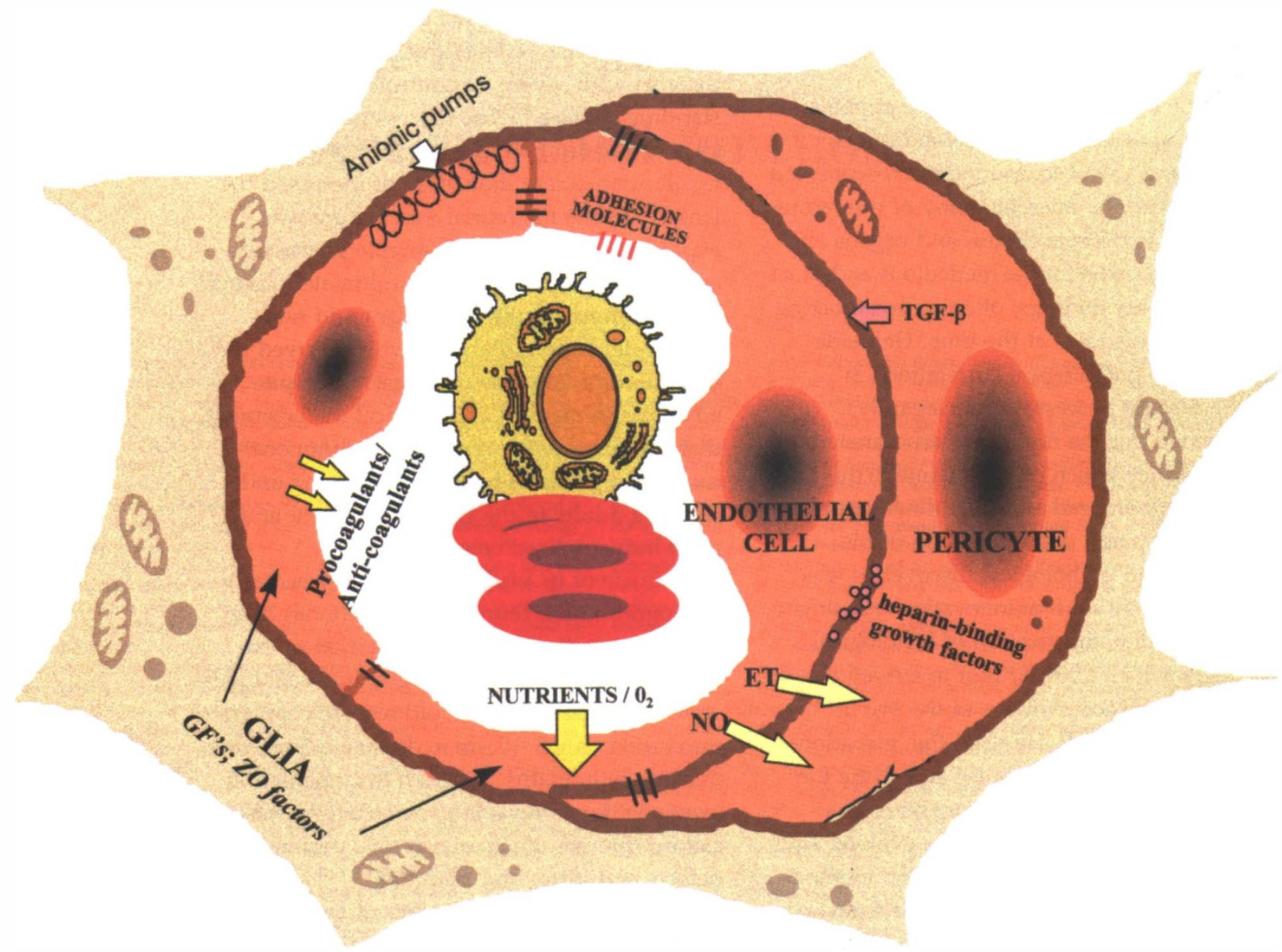

Fig. 1. Functional properties and cellular interactions of retinal capillary. 

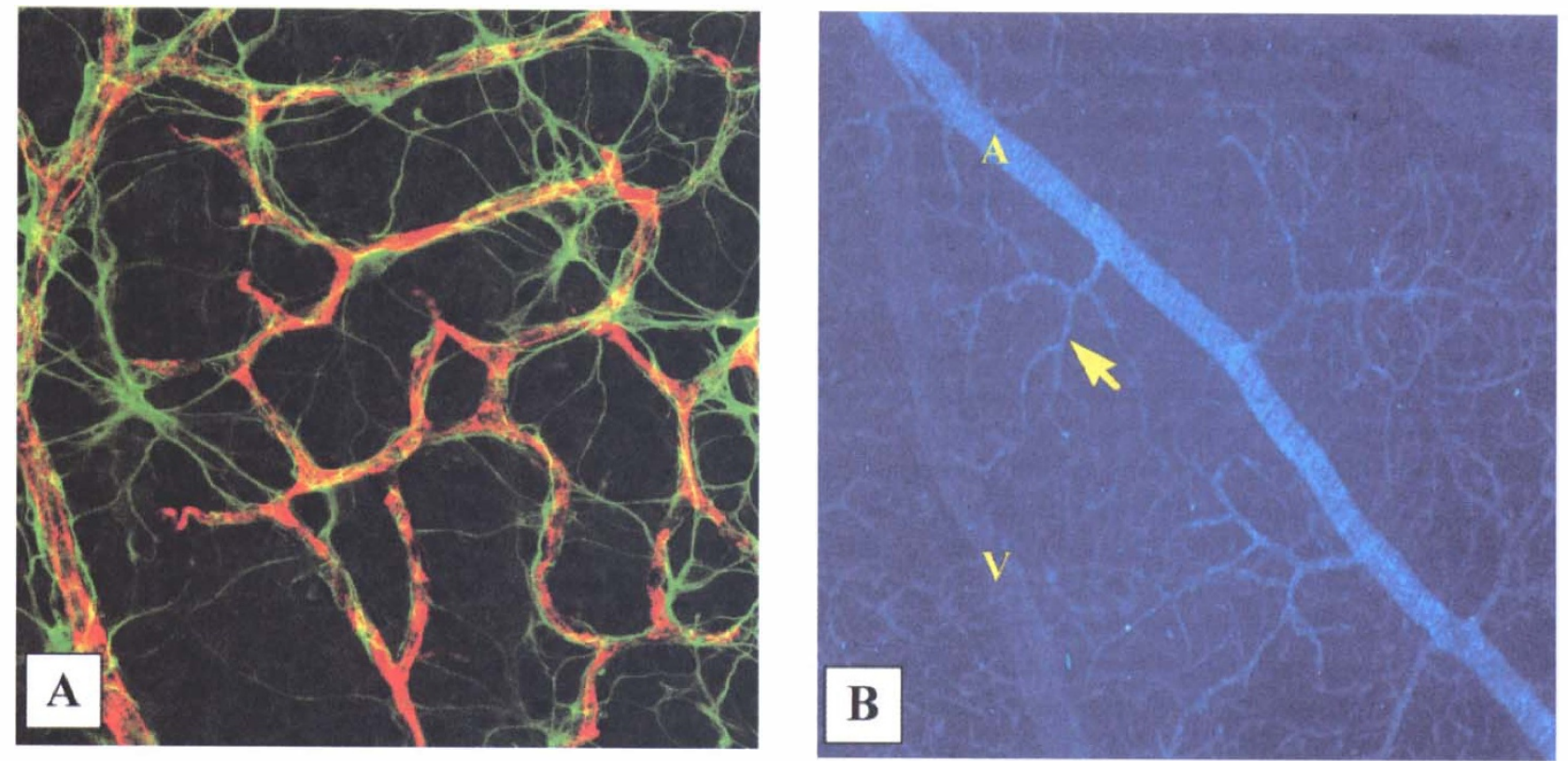

Fig. 2. (A) Confocal scanning laser micrograph retinal flat mount (mouse) showing immunoreactivity to constitutive endothelial nitric oxide synthase (red) and glial fibrillary acidic protein (green). Note the close association between astroglia and retinal capillaries. (B) Trypsin digest of normal rat retina showing endothelin 1 immunoreactivity. Staining is intense in large arterioles (A), less noticeable in precapillary arterioles (arrow) and scant in capillaries and veins $(V)$.

some of the molecular, biochemical, morphological and physiological abnormalities which occur in retinal vascular cells during diabetes and analyses how dysfunction and death might be prevented or conversely, how their survival and normal function may be perpetuated.

\section{Diabetic retinopathy: the microvascular substrate}

The retinal vasculature is unique in that its major vessels are mostly arterioles (without an internal elastic lamina), which lack an autonomic nerve supply and function in the presence of a high tissue pressure, i.e. the intraocular pressure. The capillary is the key circulatory interface within the retinal neuropile and is composed of a continuous endothelium supported by a thick basement membrane and surrounded by pericytes which have contractile and vasoregulative properties. The capillary unit is encased within neuroglia which also contribute to microvascular function and survival (Fig. 1).

Individual vascular endothelial cells are joined by occluding junctional complexes (zonulae occludens, $\mathrm{ZO}$ ) and constitute the inner blood-retinal barrier, which is structurally and functionally analogous to the blood-brain barrier. The barrier properties of the retinal vascular endothelium are influenced by the surrounding neuroglia which secrete agents to maintain tight junction formation and their specialised ZO-1 protein content. ${ }^{11,12}$

The vascular endothelial cell is central to the maintenance of normal blood flow, local rheology and the preservation of metabolic homeostasis in the neighbouring neuropile. Endothelial cells communicate directly with pericytes and smooth muscle cells via gap junctions ${ }^{13,14}$ and actively regulate capillary and arteriolar tone and calibre by elaborating vasodilators (nitric oxide (NO), adenosine, prostanoids) and vasoconstrictors (endothelin-1, angiotensin II) in response to local metabolic needs (Fig. 2). Some recent studies suggest that NO synthase (NOS)-containing neurones may have a vasoregulatory role in the retina; however, as noted, the retinal vasculature itself is devoid of an extrinsic innervation and its function is largely maintained by the autocrine and paracrine activity of its component cells. ${ }^{15}$

Although the retinal capillary unit is largely autonomous in terms of local control of rheology and tissue metabolism, blood flow into the capillary bed is determined by the state of contraction of the upstream pre-capillary arteriole whose smooth muscle cells are highly sensitive to endothelium-generated vasodilators and vasoconstrictors. Failure of the pre-capillary arteriole to regulate blood flow to the capillaries can have calamitous consequences for downstream haemodynamics, as occurs in some diabetics, and it is not surprising that microaneurysm formation predominates on the arterial side of the circulation where smooth muscle cells have been lost. ${ }^{16}$ Similarly failure and obstruction of the post-capillary venule can influence capillary hydrostatic pressures, blood flow, oxygen saturation and microvascular competence.

The vascular endothelium determines the composition of its basement membrane by secreting components of the extracellular matrix (e.g. laminin, fibronectin, entactin, collagen $\mathrm{IV}^{14}$ ) and remodelling it with degradative enzymes (e.g. collagenases and less specific matrix metalloproteases (MMPs). Basement membrane components are also secreted by pericytes, smooth muscle cells and neuroglia and the composite vascular matrix immobilises various heparin-binding paracrine growth factors (e.g. vascular endothelial growth factor (VEGF), basic fibroblastic growth factor (bFGF)) in addition to providing structural support. ${ }^{17}$ 
Local rheology is also influenced by the vascular endothelium, which has the potential to generate both pro-coagulant and anti-coagulant factors, and inhibit platelet adhesion by producing prostacyclin, and the platelet inhibiting factor NO. Fibrinolysis may also be endothelium-modified by the generation of either tissuelike plasminogen activator (TPA) or its inhibitor (TPAI). ${ }^{18}$ The vascular endothelium controls transcellular migration of blood-borne leucocytes to the neuropile by the regulation of adhesion molecules such as the selectins and ICAM-1/VCAM-1 in response to inflammatory stimuli. It is notable that $\mathrm{P}$-selectin, an adhesion molecule important to early inflammatory cell recruitment, is coexpressed with the pro-coagulant von Willebrand factor which is contained within Weibel-Palade bodies in the vascular endothelium. ${ }^{19}$

In terms of survival, retinal endothelial cells are resilient cells with a very low natural turnover. ${ }^{20}$ They can readily replicate to repair localised damage and reendothelialise defunct capillaries to a limited extent. In conditions of chronic hypoxia or ischaemia retinal vascular endothelial cells can proliferate rapidly to form sizeable preretinal neovascular membranes.

Retinal pericytes surround the endothelial tube encased within the thick basement membrane (Fig. 1). They are uniquely abundant in retinal capillaries with an endothelial to pericyte ratio approximating 1:1, compared with other microcirculations where the ratio may be as low as 1:20. Pericytes respond to endotheliumderived vasoactive agents, hormones and local metabolic needs such as $\mathrm{CO}_{2}$ and $\mathrm{pH}$ variations, ${ }^{21-23}$ and directly influence vascular endothelial cell propagation and permeability. ${ }^{14,24}$ Pericytes have a very low replicative capacity $^{20}$ and add stability to the capillary unit by inhibiting endothelial cell proliferation by the secretion of the inhibitory growth factor TGF- $\beta .{ }^{25}$ Given appropriate stimuli, pericytes demonstrate a considerable proliferative capacity as in the neovascular response of proliferative diabetic retinopathy. Pericytes and smooth muscle cells influence capillary and arteriolar lumen size by their contractile properties and fine-tune the haemodynamic control exerted by the larger upstream arterioles.

Perivascular glial cells intimately surround the capillary unit and can modify capillary form and function by secreting vasculogenic growth factors such as TGF- $\beta$ and VEGF. ${ }^{26-28}$ Glial cells also scavenge the perivascular space and are effective in removing the remains of degenerative pericytes in established diabetic retinopathy. The diabetic process may also involve the perivascular glia and neurones as various vasoactive growth factors are elevated in the retinal ganglion and glial cells during early diabetic retinopathy. ${ }^{29-32}$

\section{Hyperglycaemia: the force for change}

Risk factors for the development of microangiopathy in diabetic patients include hyperglycaemia, hyperinsulinaemia, hypoinsulinaemia, hyperlipidaemia, increased by-products of insulin secretion (pro-insulin, C

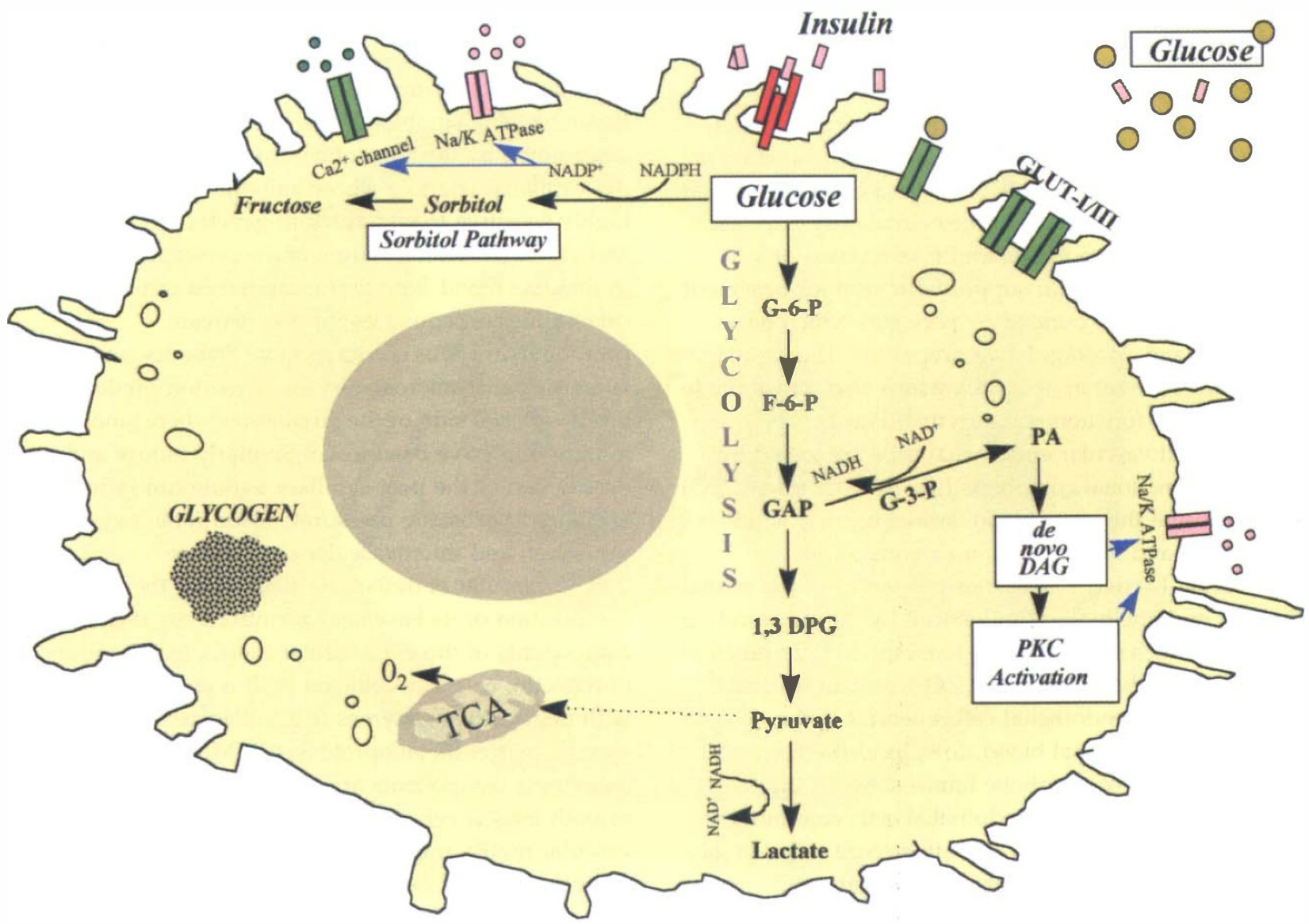

Fig. 3. Schematic representation of glycolytic pathways in a retinal vascular endothelial cell. 
peptides) ${ }_{1}^{18}$ hypertension and less well defined genetic and environmental factors. Nevertheless, despite such a range of adverse and aphysiological factors,

hyperglycaemia is unique to diabetes and the dominant force for change in terms of cell dysfunction and development of diabetic complications. ${ }^{33-35}$

\section{Metabolic and biochemical accommodations}

\section{Homeostatic mechanisms}

Regulated glucose entry

As glucose is the principal source of energy for the cell it is not surprising that its entry into the vascular endothelial cell or pericyte is facilitated by specific glucose transporter proteins (GLUT I and GLUT III) which bridge the plasma membrane of both cell types. ${ }^{36-39}$ In hyperglycaemia or hypoglycaemia these transporters can be down-regulated or up-regulated respectively to maintain constancy of intracellular glucose concentration; however, despite such limiting gateways, high concentrations of extracellular glucose in diabetes are translated to an overload of intracellular glucose sufficient to saturate some metabolic pathways (glycolysis and the tricarboxylic acid cycle), activate or exaggerate others (e.g. the polyol pathway) or attenuate others (e.g. the pentose phosphate shunt) (Fig. 3).

Insulin receptors are also present in retinal vascular cells; however, the role of insulin in glucose entry into these cells is probably less important than in other cell types. Insulin receptor binding in the retinal vasculature may have other important roles such as vasoregulation, cell survival and/or growth promotion. ${ }^{40}$

\section{Glycogen storage}

Intracellular glucose can be stored as glycogen in some retinal cells, presumably in anticipation of high metabolic demand or oxidative needs. An example is rod photoreceptor metabolism, where increased oxygen consumption and glucose utilisation occur with dark adaptation. ${ }^{41}$ In diabetic animals gross and possibly pathological accumulations of glycogen have been described in retinal amacrine, bipolar and glial cells which reflect sustained supra-normal intraretinal glucose concentrations. ${ }^{42}$ Retinal vascular cells also contain scattered glycogen granules, but even in diabetes abnormal deposits are not observed.

\section{Re-routing of gratuitous intracellular glucose}

High intake of glucose into the retinal vascular cells rapidly saturates the usual glycolytic pathways and excess hexose sugars may be diverted into other biochemical pathways which are ordinarily little used or redundant. The conversion of excess cytosolic glucose to glycogen probably contributes little to cellular euglycaemia and excess glucose is typically routed through non-glycolytic pathways. A detailed description of all the various biochemical processes involved in the intracellular metabolism of glucose is beyond the scope of this work; however, during sustained hyperglycaemia certain changes occur in key biochemical processes which have implications for the function and survival of retinal vascular cells and, furthermore, may be amenable to therapeutic manipulation, and these will be considered (Fig. 3). ${ }^{43}$

\section{Hyperglycaemia: intracellular biochemical perturbations}

Polyol pathway and pseudohypoxia

Increased flux of glucose through the polyol pathway subsequent to hyperglycaemia results, firstly, in reduction of glucose to sorbitol by aldose reductase (coupled to oxidation of NADPH to NADP+), and secondly the oxidation of sorbitol to fructose by sorbitol dehydrogenase (linked to reduction of NAD+ to $\mathrm{NADH}){ }^{43}$ The enhanced oxidation of sorbitol to fructose results in an increased cytoplasmic ratio of free NADH:NAD+. This NADH:NAD+ imbalance occurs independently of tissue oxygenation but is closely related to similar events in hypoxic tissues where there is impaired oxidation of NADH to NAD + . Williamson et al. ${ }^{44}$ describe this polyol-pathway-associated increase in the rate of reduction of NAD + to NADH with resultant rise in $\mathrm{NADH} / \mathrm{NAD}+$ ratio in vascular tissues exposed to hyperglycaemia as pseudohypoxia, because oxygen levels remain normal. Pseudohypoxia is associated with cellular imbalances in lipid metabolism, reactive oxygen species production, protein kinase $\mathrm{C}$ activation and NO production, while in tissues this translates to increased blood flow, vascular hyperpermeability and abnormal growth factor expression. ${ }^{45,46}$ Theoretically an increase in $\mathrm{NADH}: \mathrm{NAD}+$ mimics an altered lactate-pyruvate ratio and signals the need for more oxygen and triggers the release of vasodilator prostaglandins and $\mathrm{NO}$ which increase blood flow. It is argued that this enhanced blood flow is independent of tissue oxygenation and less affected by increased oxygen delivery or vasoactive stimuli and would theoretically account for the persistent vasodilatation characteristic of early diabetes. In this respect it is significant that aldose reductase inhibitors (ARIs) prevent increased blood flow in acutely hyperglycaemic and diabetic rats.

Whether the hyperdynamic retinal vascular changes in human diabetes can be attributed to pseudohypoxia is not known; however, clinical trials of ARIs have thus far shown no convincing effect in preventing the retinal vascular complications of diabetic subjects. ${ }^{47}$ Despite effective reduction in tissue sorbitol levels, ARIs have also been ineffective in preventing non-proliferative (background) retinopathy in galactosaemic or diabetic dogs. ${ }^{48}$

$\mathrm{Na}^{+} / \mathrm{K}^{+}$-ATPase

$\mathrm{Na}^{+} / \mathrm{K}^{+}$-ATPase is a ubiquitous enzyme that is an integral part of the transmembrane sodium pump involved in the maintenance of cell homeostasis and regulation of many cell functions, including contractility, 
growth and differentiation. ${ }^{49-51} \mathrm{Na}^{+} / \mathrm{K}^{+}$-ATPase is altered in the neural and vascular tissues of diabetic animals and in retinal vascular cells cultured in high glucose. Reduced enzyme activity in diabetic tissues has been linked to elevation in sorbitol levels and reduced intracellular myo-inositol. ${ }^{43,52,53} \mathrm{Na}^{+} / \mathrm{K}^{+}$-ATPases are important modulators of extracellular hydration and nerve conduction velocity and it has also been postulated that altered $\mathrm{Na}^{+} / \mathrm{K}^{+}$-ATPase activity in hyperglycaemia may impair retinal pigment epithelial cell activity and impede dehydration of the outer retina in diabetics. ARIs prevent a decrease in $\mathrm{Na}^{+} / \mathrm{K}^{+}$-ATPase activity in cultured retinal capillary endothelial cells and neurones which have been exposed to high glucose in vitro. Animal studies confirm that ARIs can prevent impaired conduction velocity in motor neurone deficiency in galactosaemic and diabetic dogs; ${ }^{54}$ however, clinical investigations have not convincingly shown that ARIs are effective against diabetic neuropathy. ${ }^{55}$

\section{Protein kinase $C$ activation}

Overactivity of the sorbitol pathway tends to deplete intracellular NADPH levels, reduce the cytosolic antioxidant glutathione and thereby enhance oxidant effects. The resultant alteration in redox state may also affect $\mathrm{NO}$ and prostaglandin synthesis and alter the activity of protein kinase $\mathrm{C}(\mathrm{PKC})$. There are a range of PKC isoforms, many of which have important roles in intracellular signal transduction for hormones and cytokines. ${ }^{56}$ Hyperglycaemia leads to de novo synthesis of diacylglycerol (DAG) in the diabetic retinal vascular endothelium which leads directly to activation of PKC, particularly the $\alpha$ and $\beta I I$ isoforms. ${ }^{57}$ In diabetic animals it has been shown that PKC activation can affect vascular permeability, basement membrane synthesis, vessel contractility, blood flow (via modulation of vasoactive agents) and coagulation, as well as modulating the actions of growth factors and influencing cell growth, motility and differentiation. ${ }^{56,58,59}$ Abnormal PKC activation is not prevented by ARIs and probably not attributable to changes in the sorbitol pathway. Because of the immediate relevance of PKC- $\beta$ II isoforms to vascular cell dysfunction in diabetes, agents have been developed to inhibit PKC- $\beta$ II activity. Recent studies

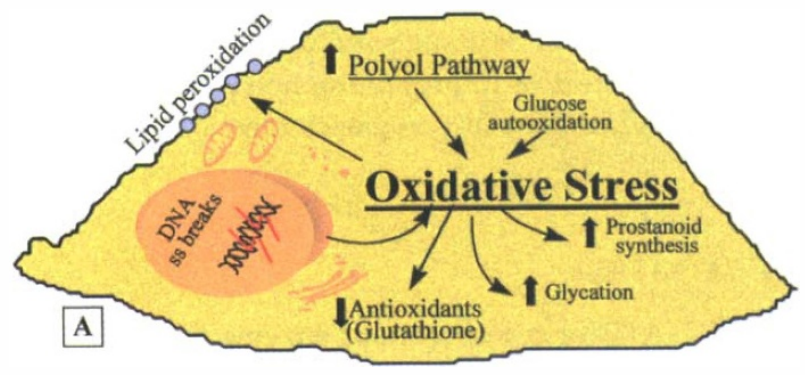

using the experimental drug LY333531 suggest that PKC$\beta I I$ activation can be curtailed and abnormal retinal haemodynamics forestalled in diabetic animals. ${ }^{60,61}$

\section{Pathophysiological mechanisms and processes}

\section{Oxidation}

The lipid-rich retinal tissues are unusually exposed to oxidative processes as the profuse choroidal and retinal circulations create an oxygen-rich milieu. Moreover, the abundant mitochondria populating the cellular and metabolically active neuropile may leak reactive oxygen species (ROS) while some ultraviolet wavelengths that irradiate the retina further exaggerate the oxidative load. Hyperglycaemia also induces or exaggerates potentially damaging biochemical processes such as glycation/ glycoxidation, polyol pathway recruitment (pseudohypoxia) and glucose auto-oxidation, all of which contribute to oxidative stress of the retina and its circulation (Fig. 4A). ${ }^{44,62}$

The generation of ROS such as superoxide anion $\left(\mathrm{O}_{2-}\right)$, hydroxyl radical (.OH) and hydrogen peroxide $\left(\mathrm{H}_{2} \mathrm{O}_{2}\right)$ can cause peroxidation of membrane lipids and destabilisation of cells, up-regulation of endothelial adhesion molecules and disruption of vasodilatory responses of the retinal circulation. ${ }^{63}$

The susceptibility of the retina to oxidative stress represents a balance between pro- and anti-oxidant factors. Levels of anti-oxidants may be diminished by hyperglycaemia and retinal glutathione concentrations may be reduced in advance of structural changes in retinal vascular cells. ${ }^{64,65}$ Sharpe et al. ${ }^{66}$ suggest that retinal pericytes are less susceptible to lipid peroxidation than aortic smooth muscle cells in high glucose medium, even though glutathione levels are reduced in both cell types. Interestingly it has been suggested that there is not a generalised 'oxidative stress' in diabetes, as in one study some of the products of oxidative damage did not alter between diabetic and non-diabetic patients, probably as a result of up-regulation of endogenous antioxidant and free radical scavenger molecules. ${ }^{67}$

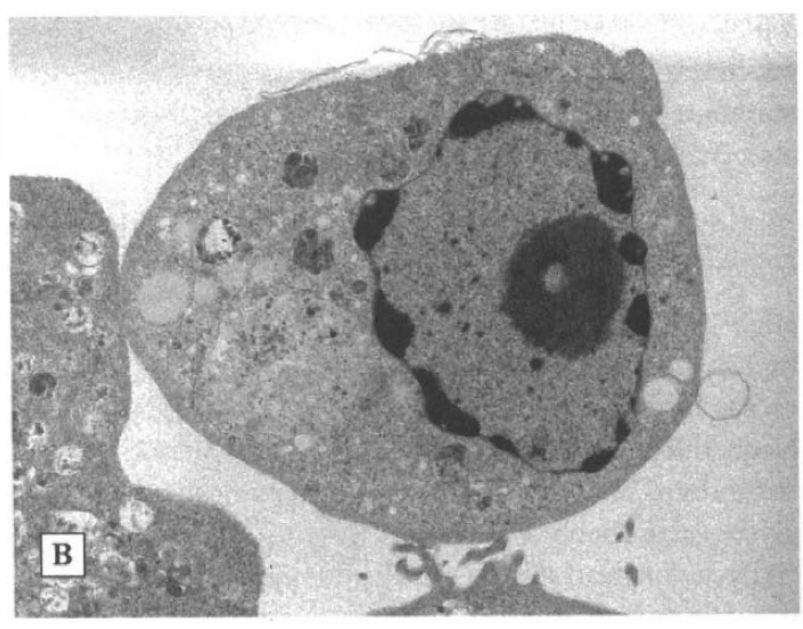

Fig. 4. (A) Hyperglycaemia-related oxidative reactions in retinal vascular cells. (B) Hydrogen-peroxide-induced apoptosis in a cultured vascular endothelial cell. There is extreme condensation of nuclear heterochromatin. 


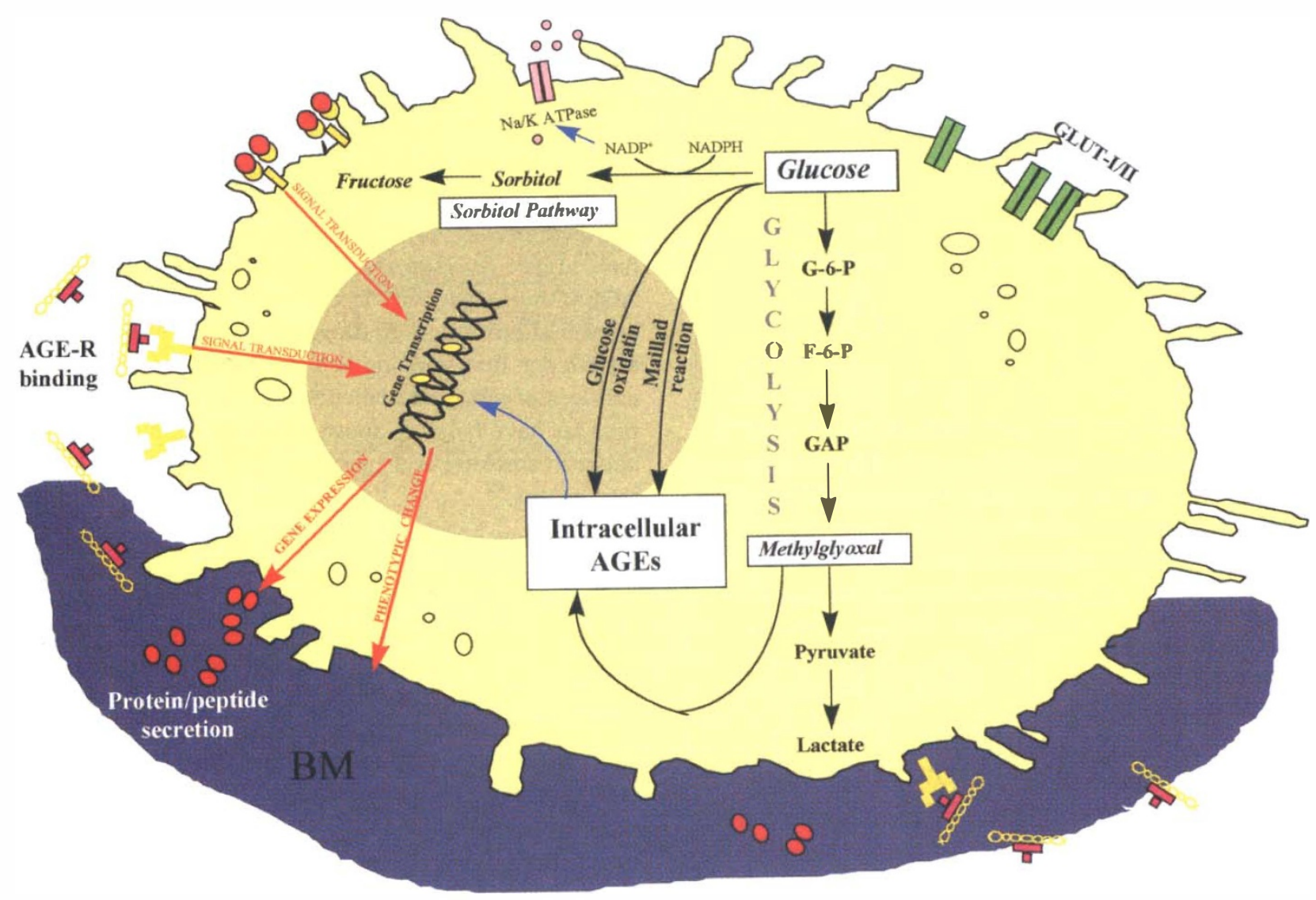

Fig. 5. Non-enzymatic glycation pathways and reactions in retinal vascular cells.

It is not known to what extent oxidative stress impairs retinal vascular function in diabetes or contributes to diabetic retinopathy. Vascular endothelial cell and pericyte activities, however, may be modified by their exposure to high concentrations of ROS as a consequence of hyperglycaemia ${ }^{62}$ and apoptosis can be induced in these cells by severe oxidative stress (Fig. 4B). ${ }^{68}$

Moreover, Lyons et al. demonstrated that oxidised low density lipoprotein was toxic to retinal microvascular endothelial cells and pericytes, while glycoxidised low density lipoprotein had even more harmful effects in these cells. ${ }^{69}$

In established diabetic retinopathy, damaging oxidative processes may be heightened by haemorrhage and leaching of transition metals into the retinal extracellular space and neuropile, and laser photocoagulation induces its own intense local oxidation with precipitation and coagulation of irradiated tissues.

Oxidative stress can be ameliorated by using antioxidants and there is tentative experimental evidence that free radical scavengers such as vitamin $C$ and vitamin $\mathrm{E}$ may favourably influence the natural course of the disease process; ${ }^{70}$ however, as yet there is no clear evidence that anti-oxidants prevent or modify the development of clinical diabetic retinopathy. ${ }^{71}$

\section{Non-enzymatic glycation}

High concentrations of glucose in cells and extracellular spaces accelerate the spontaneous formation of glucose adducts to proteins and other amine containing molecules through the Maillard reaction. Early stages of non-enzymatic glycation products are freely reversible and can lead to 'Amadori products', an example of which is $\mathrm{HbA}_{1 \mathrm{c}}$ However, with time these intermediates convert to irreversibly modified cross-linked condensation products named 'advanced glycation endproducts' (AGEs) (Fig. 5).

Traditionally, AGEs form on long-lived proteins such as collagens and lens crystallins where their concentration strongly correlates with the degree of glycaemic control and ageing. More recently AGEs have been quantified in serum where they may be detected on shorter half-life proteins such as haemoglobin, albumin and plasma lipoproteins and at elevated levels in diabetics. $^{72}$

More recently there has been an emphasis on the role of glycoxidation products which form via glycation and associated oxidation reactions with proteins. ${ }^{73}$ Also, there has been significant recognition of the rapid formation of AGEs through the action of strongly glycating reactive intermediates such as 3-deoxyglucosone and methylglyoxal which can form AGE adducts in days rather than months as with the relatively 'weak' glycating glucose. Many cells are imbued with receptors for AGEs, including retinal 
vascular endothelial cells and pericytes, and under normal circumstances established scavenging mechanisms eventually eliminate them from the body.

AGEs can modify retinal vascular function in a variety of ways. Glycation of plasma proteins can induce a procoagulant state and alter blood viscosity and tissue oxygenation. The complexing of glucose to basement membrane collagen alters its thickness (reduced degradability), antigenicity, permeability, heparin sulphate proteoglycan composition, compliance and perhaps interactions with heparin-binding growth factors such as VEGF and b-FGF. Furthermore, exposure of vascular cells to AGEs causes an up-regulation of basement membrane components. Glycated basement membrane components, collagen IV, laminin, vitronectin, etc., are also resistant to remodelling by vascular endothelial cell proteases ${ }^{74-76}$ and glycated matrix may influence recognition and binding of surface receptors which may affect endothelial cell migration and proliferation. $^{77}$

Many cell types express AGE receptors and act as important AGE scavengers, removing senescent, modified molecules from the circulation and tissues. Also AGE binding to their receptors can modulate many important cell responses such as increased secretion of cytokines (TNF $\alpha$, IL-1) and growth factors and upregulation of ECM gene expression. ${ }^{78}$ While fibroblasts, macrophages and leucocytes express AGE receptors, it is significant that the vascular endothelium possesses distinct AGE receptors which are regulated by AGE exposure and induce AGE-mediated vascular responses. $^{79}$

Less is known about the intracellular effects of AGEs on the retinal vasculature, although pericytes and vascular endothelial cells express AGE receptors ${ }^{80}$ which differ in their response to AGE ligands. AGE modified proteins can induce changes that promote matrix over production, focal thrombosis and vasoconstriction in the retinal vasculature. ${ }^{77}$ Cross-linking of primary amine groups of nucleic acids have major consequences for vascular cells and some studies show that single-strand DNA breaks and impaired DNA repair can occur on exposure of human vascular endothelial cells in vitro to high glucose levels. ${ }^{81}$ It is also known that AGEs impair both activity of $\mathrm{NO}$ and expression of endothelial nitric

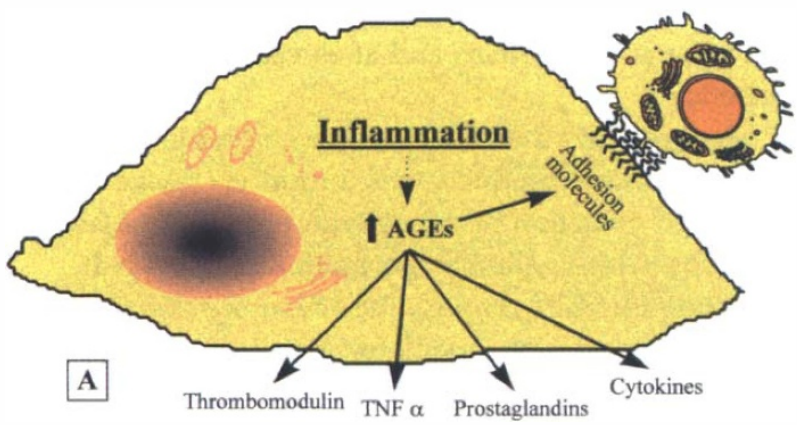

oxide synthase (eNOS) by vascular endothelial cells ${ }^{82,83}$ and may contribute to the failure of autoregulatory control in diabetic retinal vasculature.

It has recently been shown that certain components of cigarette smoke can react with plasma components and extracellular matrix to form covalent adducts with many of the properties of AGEs. ${ }^{84}$ Smokers have been shown to have higher levels of glycated lens proteins and more AGE immunoreactivity in coronary arteries than nonsmokers, ${ }^{85}$ and these findings are consistent with the knowledge that smoking is a risk factor for proteinuria and loss of vision in diabetics, ${ }^{86}$ although most studies thus far have failed to show a definite connection between smoking and progression of diabetic retinopathy. ${ }^{87}$

\section{Osmotic imbalance}

Aphysiological changes in cellular and extracellular hydration are a feature of diabetes inspired by rapid changes in blood glucose. High accumulations of intracellular sorbitol can induce pathological changes in lens fibres; however, concentrations in retinal vascular cells have not been shown to be sufficient to induce osmotic gradients capable of disrupting cell architecture or function.

\section{Hypoxia}

In view of the profuse and autoregulated retinal circulation, hypoxia is probably not a significant factor in inducing the early vascular cellular changes in diabetes; however, Linsenmeier ${ }^{88}$ using oxygen microelectrodes has found evidence that retinal hypoxia can occur in diabetic cats concomitant with endothelial cell death and macrophage/leucocyte plugging of capillaries, but before there is evidence of capillary fallout. In states of hypoxia the retina is known to respond by increasing expression of VEGF, ${ }^{89}$ probably mediated by adenosine $\mathrm{A}_{2}$ receptor activation. ${ }^{90}$ Upstream to this, there is activation of the hypoxia-regulated transcription factor hypoxia-inducible factor $1 \alpha$ (HIF- $1 \alpha$ ) which binds to a hypoxic response element leading to increased

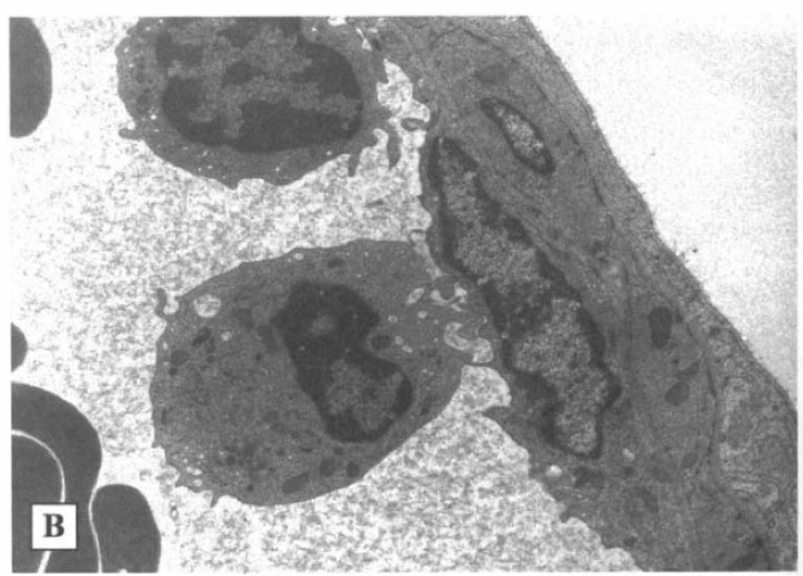

Fig. 6. (A) Inflammation-induced reactions in retinal vascular endothelium in diabetes. (B) Lymphocytes establish adhesions with retinal vascular endothelial cells in a retinal arteriole of a diabetic dog. 


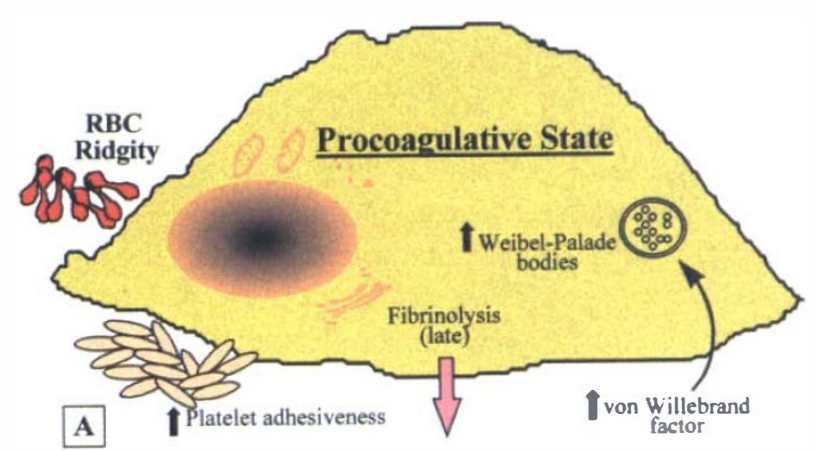

Fig. 7. (A) Possible procoagulative factors in a diabetic retinal capillary. Palade bodies in the vascular endothelium.

transcription of VEGF. While this is mostly recognised in tumours and in vitro systems it has also been demonstrated in the hypoxic retina. ${ }^{91}$

In advanced ischaemic diabetic retinopathy hypoxia almost certainly contributes to increased expression of angiogenic growth factors such as VEGF which ultimately leads to neovascularisation. ${ }^{89,92}$ Hypoxia may also influence the viability of ganglion cells in the diabetic retina by increasing glutamate release and inducing excito-toxicity changes in cells, due to uncensored $\mathrm{Ca}^{2+}$ influx, although it has been suggested that retinal ganglion cells increase expression of the $72 \mathrm{kDa}$ heat shock protein which confers some tolerance to hypoxia and excitotoxicity. ${ }^{93}$

\section{Inflammation}

Certain hyperglycaemia-linked metabolic processes generate mediators of inflammation (prostaglandins, etc.) and AGEs can induce pro-inflammatory cytokines and adhesion molecules from macrophages and vascular endothelial cells (Fig. 6). Various adhesion molecules for inflammatory cells may also be expressed in early diabetes and some studies have shown that activated and adherent leucocytes become entrapped in capillaries and cause occlusion in early experimental diabetes. ${ }^{94-97}$ Inflammatory cells may also accumulate in microaneurysms and monocytes/macrophages are sometimes associated with intra- and preretinal neovascularisation, where presumably they generate angiogenic growth factors. However, in early clinical diabetes inflammation is not a biomicroscopical feature and where cell loss does occur it is probably by a process of apoptosis which does not excite a significant or identifiable inflammatory response.

\section{Pro-coagulative state}

The coagulative properties of the blood may be affected in early diabetes as evidenced by increased platelet activation, aggregation and eicosanoid production, and in later ischaemic disease the altered balance between coagulation and fibrinolysis leads to vascular instability

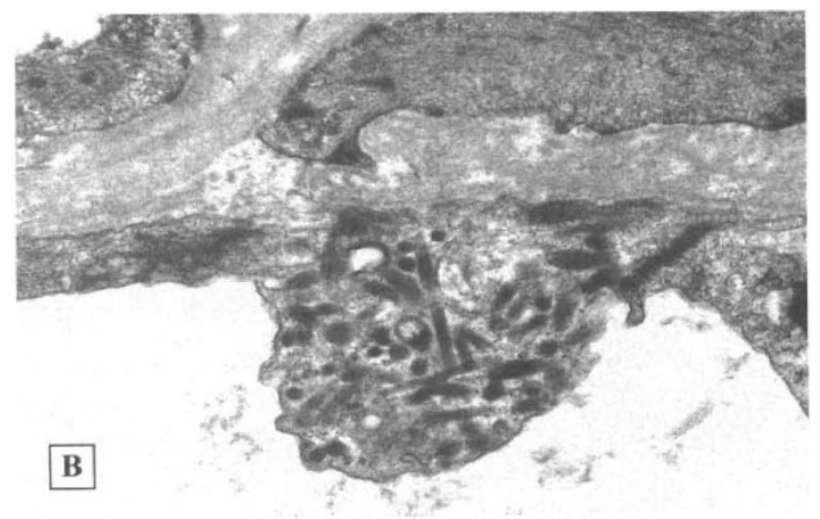

(B) Retinal venule of a diabetic dog showing dense collections of Weibeland occlusion (Fig. 7). ${ }^{18,98}$ Hyperglycaemia may perturb the coagulation cascade by increased oxidative stress, glycation (which may increase tissue factor activity) ${ }^{78}$ and impairment of heparin sulphate proteoglycan synthesis. Polymorphonuclear leucocytes may also be less deformable in diabetes ${ }^{99}$ and are more adherent to the vascular endothelium, thereby increasing the likelihood of occlusion of small capillaries. The vascular endothelium can alter local rheological conditions by the elaboration of pro- and anti-clotting factors as illustrated by a significant increase in Weibel-Palade bodies containing von Willebrand factor in diabetic retinal vessels (Fig. 7). ${ }^{100}$ Intraluminal thrombin and fibrin fragments are found in advanced ischaemic retinopathy and may act as strong stimulators of vascular endothelial cell growth and important instigators of capillary reendothelialisation and angiogenesis. ${ }^{18}$

It is not known to what extent clotting or rheological abnormalities contribute to the development of diabetic retinopathy or at what point in the disease process their effect is crucial to circulatory failure. Most evidence suggests that in early diabetic retinopathy rheological changes contribute to circulatory stasis, whilst in late retinopathy both rheological and coagulative abnormalities contribute to vascular occlusion and subsequent ischaemic and proliferative events. To date therapeutic manipulation of rheological and coagulative events has not had a significant place in the management of diabetic retinopathy.

\section{Altered vascular cell kinetics}

The survival of cells during severe and sustained hyperglycaemia depends on internal factors such as proper transcriptional/translational regulation, an acceptable synthetic capability, fully integrated metabolic pathways and intact plasma membranes. External signals from the extracellular matrix and paracrine secretions from adjacent cells coupled with systemic endocrine stimulation are also essential elements of cell regulation and survival.

Abnormal metabolism of the cell may be heralded by changes in gene expression modulated by DNA damage, accumulation of inappropriate metabolic products, 

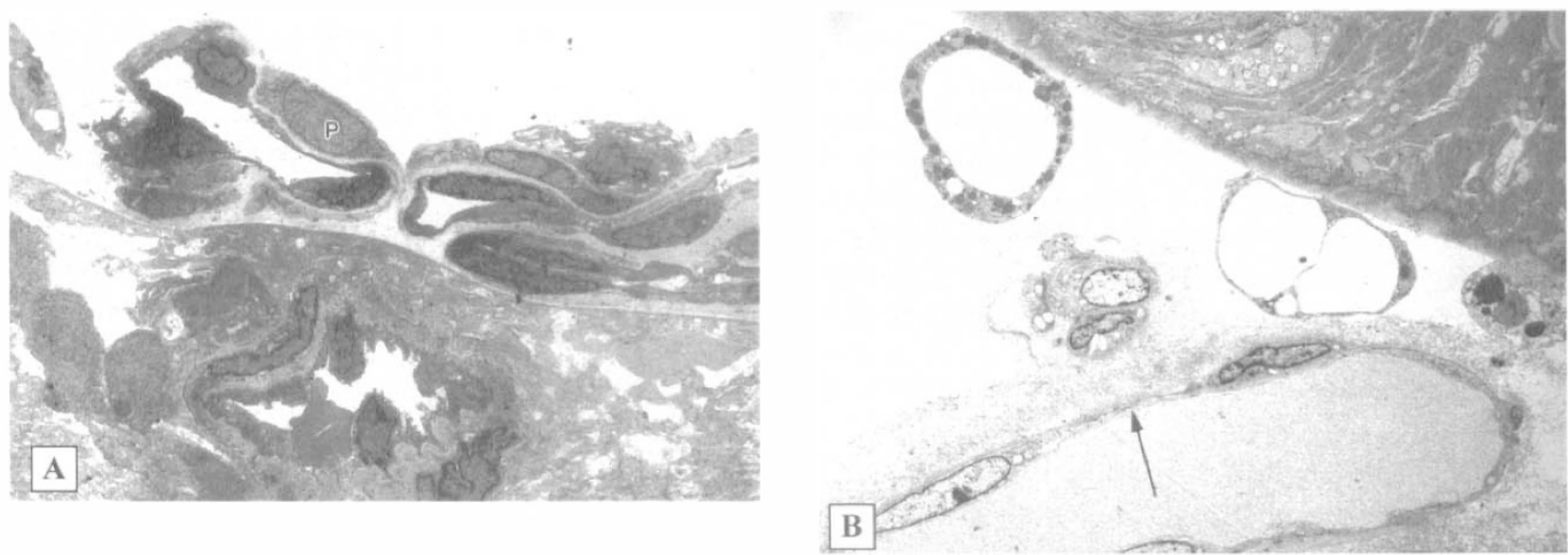

Fig. 8. (A) Mouse with oxygen-induced retinopathy at post-natal day 20. Preretinal new vessels have basement membranes and attendant pericytes $(P)$. (B) Established preretinal new vessel in proliferative diabetic retinopathy (human). The vascular endothelium is thinned and fenestrated (arrow).

biochemical perturbations and altered turnover of cell components. At a cellular level, hyperglycaemia can either directly or indirectly influence cell proliferation, migration and angiogenesis on the one hand or cell dysfunction and death on the other.

\section{Cell proliferation/migration}

Ordinarily retinal vascular cells are quiescent $\left(\mathrm{G}_{0}\right.$ stage of the cell cycle) with a very low level of endothelial cell and pericyte replication required only to make good wear and tear damage to the vascular lining. ${ }^{20}$ In severely diabetic animals retinal vascular endothelial cell turnover is markedly increased although pericytes show significantly less replicative capacity. ${ }^{20}$ Focal endothelial cell proliferation probably occurs in ischaemic retinopathy as some defunct channels recanalise and new vessels form. These are categorised clinically as intraretinal microvascular abnormalities (IRMAs) and are a feature of significant inner retinal ischaemia and a risk factor for the development of preretinal and papillary new vessels. Migrating endothelial cells can occasionally be observed in vivo, in the act of proteolytically digesting and breaching their basement membranes, and in proliferating preretinal new vessels the endothelial cells are highly active and have few pericyte contacts (Fig. 8). Activated and migrating endothelial cells require an appropriate balance of local growth factors and their specific receptors, access to lowresistance pathways and specialised interaction with the extracellular matrix.

\section{Cell death}

In 1974 Vracko and Benditt ${ }^{101}$ proposed that the typically layered structure of the basement membrane in diabetic capillaries represented evidence of accelerated death and regeneration of the endothelium. Later, Sharma et al. ${ }^{20}$ demonstrated a 3-fold increase in endothelial cell turnover in rats after 6 months of diabetes and concluded that the distribution of $\left[{ }^{3} \mathrm{H}\right]$ thymidine-labelled cells in trypsin digests reflected increased endothelial cell death and replacement rather than uncontrolled proliferation. However, positive evidence of increased vascular cell death in diabetic retinopathy was lacking until a recent study by Mizutani et al. ${ }^{102}$ which showed an increase in terminal deoxynucleotidyl transferase-mediated d-UTP nick end labelling (TUNEL) of apoptotic cells in trypsin digest preparations from diabetic patients and experimental animals. Although there is evidence that in some circumstances TUNEL may stain necrotic cells, the latter study suggests that the mode of cell death in diabetic retinopathy is largely one of apoptosis.

\section{Apoptosis}

Apoptosis is a genetically 'programmed' and controlled form of active death, which in most cell types relies on a constitutively expressed, but normally inactive, death machinery. ${ }^{103,104}$ Although many induction pathways have been identified for apoptotic cell death the central 'executioner' is now thought to be a complex interaction of a cascade of cysteine proteases (caspases) and other factors released from dysfunctional mitochondria. ${ }^{105}$ Apoptosis may be likened to cell suicide and results from activation of the death apparatus, either by withdrawal of survival signals, or by receipt of death commands. Failure of affirmative stimuli mediated by auto- or paracrine cell-specific growth/survival factors, or loss of normal matrix interactions through, for example, integrin receptors, may induce apoptosis by default.

Alternatively, receipt of exogenous death-inducing signals through receptors of the TNF family may have the same result. Death stimuli such as ROS may also arise internally, for example as a result of DNA damage detection mediated by the p53 transcriptional factor. ${ }^{106}$ Apoptosis is typified by distinctive morphological signs which include cell shrinkage, extreme condensation of the nuclear chromatin and blebbing of the plasma membrane with the associated dissection of the cell into membrane-bound packets or apoptotic bodies (Fig. 4B). Although apoptotic bodies may be engulfed by 'professional' phagocytic cells such as macrophages, they are also internalised by the normal neighbours of the 
dying individual. In this way apoptosis provides a 'clean' form of cell death in which cell constituents are sequestered and inflammatory cell recruitment is circumvented. In both clinical and experimental diabetes the increase in apoptosis of retinal vascular endothelial cells/pericytes, as measured by TUNEL positivity, precedes histological evidence of retinopathy. ${ }^{102}$

\section{Necrosis}

In contrast to apoptosis necrosis is usually considered a passive degeneration induced by overwhelming toxic or physical insults, often by the same agents which at lower levels may induce apoptosis, e.g. ionising radiation. In necrosis the gross morphological changes are diametric to apoptosis with uncontrolled swelling of the cell cytoplasm and intracellular organelles. Dominant in this process is the rupture of lysosomal compartments with release of acid hydrolases. Necrotic cells also experience a rapid loss of plasma membrane integrity, with release of pro-inflammatory cell products into the tissue spaces. This precipitates a localised inflammatory response and activates scavenging systems in the retinal neuropile to remove redundant and non-functioning cell debris.

Although certain oxidative events, perhaps mediated by dysfunctional leucocytes, can be sufficiently acute to overwhelm retinal vascular cells and induce necrosis in diabetes, it seems more likely that prolonged hyperglycaemia-associated cellular dysfunction and disruption of survival signals through glycation of the extracellular matrix predispose to an apoptotic death scenario.

\section{Functional changes}

The retinal vasculature is well designed to satisfy the high metabolic and respiratory requirements of the inner retina and maintain strict control over the biochemical balance of the extracellular space of the retinal neuropile. It reacts flexibly to changes in the systemic circulation such as reduced blood oxygen saturation, hypercapnia and hypertension and responds swiftly to altered circumstances in local tissue metabolism, i.e. autoregulation of blood flow. The retinal microcirculation with its high endowment of smooth muscle cells and pericytes modifies blood flow according to local tissue needs and intrinsic autoregulatory processes are controlled by upstream haemodynamic events via the release of vasoactive agents. The retinal vascular endothelium is a key player in controlling blood flow by virtue of its direct and indirect ionic, biochemical and physical contacts with adjacent pericytes in capillaries, and smooth muscle cells in arterioles.

Sustained hyperglycaemia influences many aspects of retinal vascular function, particularly autoregulation of blood flow, permeability and local rheology. ${ }^{94,107-110}$ However, changes are potentially reversible in early diabetes and generally not sufficient to compromise necessary visual functions prior to significant cell loss, vascular occlusion and development of retinopathy.

\section{Blood flow alterations}

Experimental and clinical observations have shown that retinal blood flow and oxygen consumption increase following acute hyperglycaemia and decline when blood sugar levels are normalised with insulin or other intervention to lower blood glucose. ${ }^{111-114}$ Long-standing hyperglycaemia has been shown adversely to affect autoregulation in diabetic retinopathy. ${ }^{115}$ Studies of diabetic patients without retinopathy mostly confirm that retinal blood flow is significantly reduced compared with normal subjects. ${ }^{94,112,115,116}$ When blood sugar levels are incrementally raised in non-retinopathic diabetics (using glucose clamp techniques) blood flow increases, but not beyond upper limits noted in normals. ${ }^{112}$ In established diabetic retinopathy blood flow may increase ${ }^{117}$ however, as capillary fallout and ischaemia develop blood flow significantly declines. ${ }^{118}$ Following panretinal photocoagulation, which dramatically reduces the area of serviceable capillary bed and metabolic requirements of the atrophic retina, there is a further striking reduction in retinal blood flow. ${ }^{117}$

Vascular control in early diabetes is probably affected by oxygen need and the interplay of various vasoactive substances whose release and effects may be altered by aphysiological glycaemia. ${ }^{22} \mathrm{NO}$, a vasodilator, and ET-1, a potent vasoconstrictor peptide, are probably the key players in controlling vessel calibre and blood flow in the retinal circulation, ${ }^{22,119-124}$ although other metabolites such as prostacyclin, thromboxane $\mathrm{A}_{2}$ and other eicosanoids may contribute to haemodynamic change. ${ }^{22}$ Adenosine, which accumulates under hypoxic and ischaemic conditions, ${ }^{125}$ causes relaxation of pericytes through the activation of its $\mathrm{A}_{2}$ receptors and it has been proposed that adenosine may contribute to the 'finetuning' of the retinal circulation. ${ }^{126}$ Insulin may also be associated with retinal vasodilatation through $\mathrm{NO}$ release and modification of $\mathrm{Ca}^{2+}$ channels and/or regulation of endothelin-1 (ET-1) expression. Most studies show that hyperglycaemia inhibits retinal pericyte contractility. ${ }^{127}$

ET-1 and ET-3 secretion is increased in retinal microvascular endothelial cells exposed to high glucose concentrations in vitro and in the vascular endothelium of diabetic rats. ${ }^{123,128}$ ET-1 and ET-3 induce pericyte contraction and constriction of small arterioles, although when conditioned to a glucose-rich environment pericytes become somewhat resistant to ET-1 as demonstrated by impaired contractile responses. ${ }^{119,121,129}$ It has also been shown that intravitreal injection of ET-1 and ET-3 reduces blood flow in diabetic rats ${ }^{121}$ and blockade of the $\mathrm{ET}_{\mathrm{A}}$ receptor, which mediates the constrictor effects of ET-1, normalises retinal blood flow. It is likely that an increase in endogenous expression of ET- 1 and ET- 3 contributes to the reduction of retinal blood flow reported in the early stages of diabetes. ${ }^{124}$

Inadequate blood flow, hypoxia and hypercapnia potentiate the production of NO and adenosine which relaxes pericytes and smooth muscle cells. ${ }^{22}$ It has been 
suggested that these two agents normally maintain the retinal vasculature in a tonic state of mid-dilatation. The precise biochemical events leading to alteration in the release of vasoactive substances in hyperglycaemia are still ill-understood; however, it has recently been proposed that elevated DAG and the resultant sustained activation of PKC- $\beta$ II in hyperglycaemia represents a major causative factor in the abnormal retinal haemodynamics in diabetic rats. This proposition is consistent with the central role of PKC in the transduction pathways of vasoactive agents such as ET-1 and NO. Thus, it can be appreciated that changes in retinal blood flow in early diabetes follow disruption of the physiological balance between competing vasoactive agents.

In chronic diabetes other systemic haemodynamic factors become important such as abnormal blood rheology, and increased leucocyte adhesion to the vascular endothelium which conspire to increase vascular resistance to flow. ${ }^{130}$ Once structural changes occur in the retinal vasculature, particularly basement membrane thickening and loss of pericyte and smooth muscle cells, the capillary bed becomes unresponsive and autoregulative capacity gradually fails. Subsequent occlusion of capillary beds and development of preferential pathways may result in uncontrolled blood flow and further haemodynamic insult to the residual vasculature.

\section{Altered vascular permeability}

Increased retinal microvascular permeability is a feature of established diabetic retinopathy and chronic accumulation of extracellular fluid at the macula is a common cause of visual impairment in both insulindependent and non-insulin-dependent diabetes. The retinal pigment epithelium appears more durable in diabetes than the retinal vascular endothelium and although some outer barrier failure has been described in diabetic patients ${ }^{131}$ it is probably not an important factor in the genesis of early maculopathy.

The point in the diabetic process at which the normally 'tight' retinal microcirculation becomes excessively permeable is not known, although early vascular incompetence has been reported in diabetic and galactosaemic animal models using tracers and in some pre-retinopathic diabetic subjects using vitreous fluorophotometry. ${ }^{132}$ Subtle alterations in microvascular permeability are difficult to discern clinically, as gratuitous fluid in the extracellular space may be expeditiously removed by vascular endothelial and retinal pigment epithelial $\mathrm{Na}^{+} / \mathrm{K}^{+}$-ATPase pumps. However, when leakage overwhelms the compensatory mechanisms fluid accumulates in the retinal extravascular and extracellular spaces and increased retinal thickness can be detected biomicroscopically and quantified with ultrasound or scanning laser techniques.

The cellular basis for increased vascular permeability in diabetes is undecided; however, it is probably a combination of failure of the occluding intracellular junctions, ${ }^{133,134}$ heightened transendothelial fluid dynamics and enhanced vesicular transport. ${ }^{135}$ In advanced disease, fenestration of the normally 'tight' vascular endothelial cells may occur ${ }^{136}$ and in some damaged capillaries, i.e. microaneurysms, there is complete loss of endothelial integrity. Increased vascular permeability may also reflect abnormal expression of vasopermeability factors (e.g. VEGF or histamine) and untoward haemodynamic events such as venous occlusion. The modified chemistry of the microvascular environment together with altered pericyte and glial cell function may also influence the permeability characteristics of the inner blood-retinal barrier.

\section{Haemodynamic stresses}

Capillary endothelial competence and integrity may be challenged by increased hydrostatic pressure due to failure of the upstream pre-capillary arterioles to regulate blood flow. Loss of smooth muscle cells in pre-capillary arterioles $^{16}$ and impaired autoregulation may impose unsustainable shear stresses on the downstream delicate and unprotected capillary bed. Uncontrolled blood pressure, increased turbulence and shear stress and exaggerated blood viscosity can physically elongate vascular endothelial cells and increase their permeability. ${ }^{76,137-139}$ Similarly venous occlusion or stasis may cause an immediate outpouring of fluid due to increased hydrostatic pressure, coupled with an associated hypoxic or ischaemic environment. Increased permeability following vein occlusion may be more a function of the hypoxic insult than the sustained elevation of hydrostatic pressure. Vascular dilatation associated with the unstable circulation of advanced retinopathy also vastly increases the capillary surface area to be serviced by the vascular endothelium and stresses both their intracellular junctions and cell barrier functions. Whether retinal capillaries suffer significant shear stress damage in diabetes is unproven.

\section{Growth factor influences}

It is becoming increasingly recognised that vascular permeability can be dramatically altered by the local action of growth factors, hormones and intraocular inflammatory mediators on the microvasculature. Various growth factors and cytokines can alter vascular permeability as illustrated by the intravitreal injection of insulin-like growth factor (IGF-1) which can cause profound changes to the structure and permeability of normal retinal vessels in experimental animals. ${ }^{140}$ Growth factors such as b-FGF, epidermal growth factor (EGF), TGF- $\beta$ and platelet-derived growth factor (PDGF) all have established and important biological effects on the normal function and survival of retinal vascular and paravascular cells (Fig. 9). Their precise role in the evolution of diabetic retinopathy is unclear at present.

VEGF, formerly known as vascular permeability factor (VPF), is a ubiquitous, pluripotential growth factor, expressed by vascular, neuronal and glial cells ${ }^{141}$ 


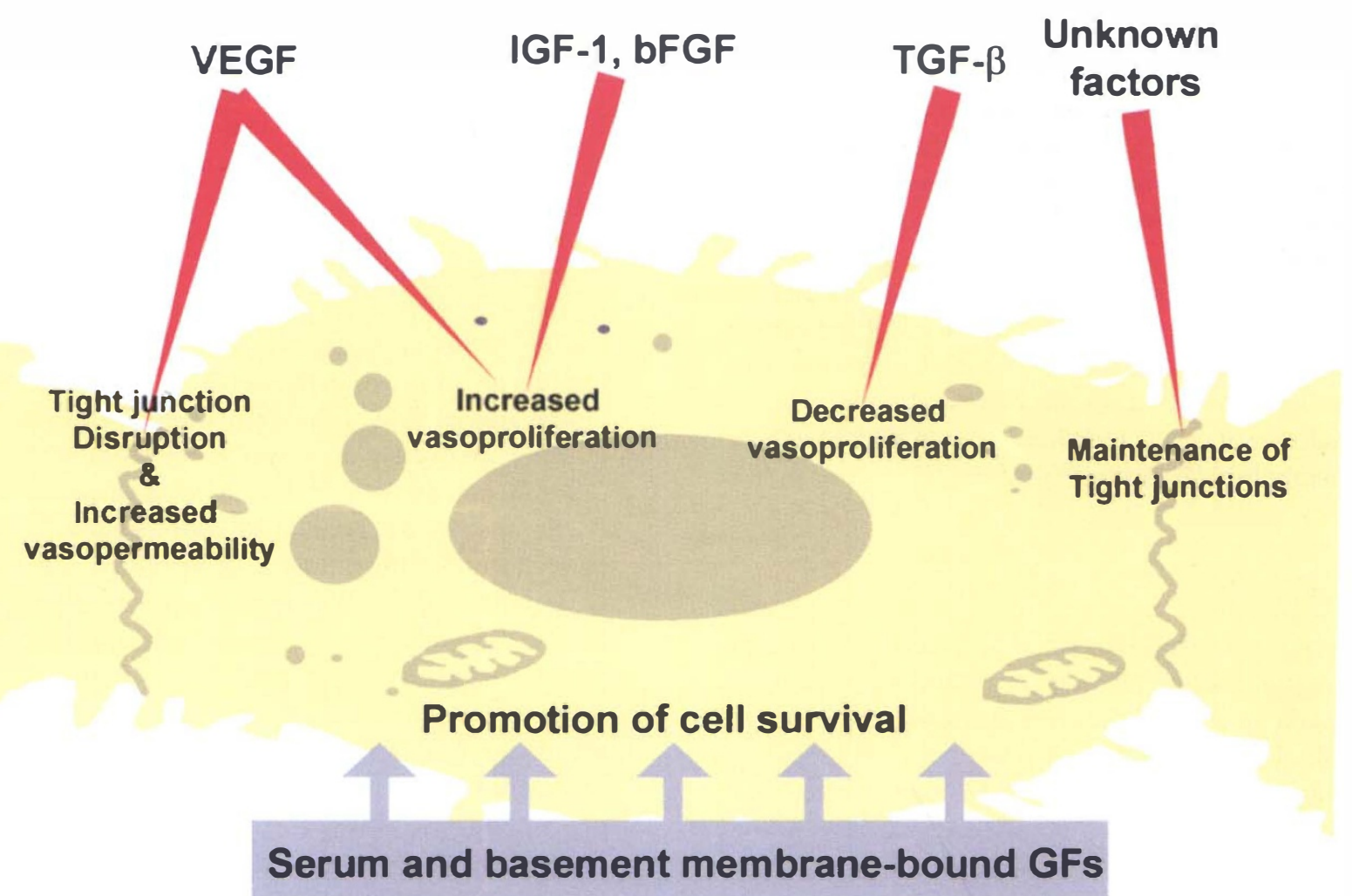

Fig. 9. Proposed role of growth factors in retinal vascular endothelial dysfunction in diabetic retinopathy.

and strategically placed to influence microvascular form and function and act as a survival factor for retinal vascular endothelial cells. ${ }^{142}$ It is fast being recognised as a key growth factor involved in the genesis of both exudative and proliferative diabetic retinopathies. ${ }^{143-145}$ VEGF is a glycopeptide with sequence homology to other members of the VEGF family which include VEGF$B, C, D$, placental growth factor and PDGF and binds with high affinity to specific tyrosine kinase receptors (Flt-1 and KDR) on vascular endothelial cells. VEGF undergoes alternative mRNA splicing to yield at least five isoforms, several of which bind to heparin sulphate proteoglycan, a key component of basement membranes. VEGF may act in a paracrine or autocrine fashion and by virtue of its basement membrane binding properties is concentrated at the endothelial/pericyte interface.

Hyperglycaemia increases the production of $\mathrm{VEGF}^{45}$ in the retina, particularly by retinal vascular endothelial cells, pericytes, smooth muscle cells, retinal pigment epithelial cells and neuroglia. ${ }^{27,146,147}$ Hyperglycaemiainduced VEGF gene expression and peptide production in human smooth muscle cells has been shown to be mediated by a PKC-dependent mechanism. ${ }^{148}$ Crucially, VEGF expression is triggered by hypoxia, ${ }^{89,92,149,150}$ probably mediated by adenosine ${ }^{123}$ through transcriptional regulation by HIF- $1 \alpha$, and decreased in conditions of hyperoxia. ${ }^{151}$ The biological effects of VEGF are dictated by the nature of its source cells, the levels secreted and the receptor expression by target cells. Known pathophysiological effects of VEGF are neovascularisation and increased permeability of blood vessels, and it also appears to have key roles in vascular cell survival and maintenance of phenotype in fenestrated endothelia such as choriocapillaris, renal glomerulus and choroid plexus, ${ }^{89,150,152,153}$ vascular cell survival and angiogenesis. ${ }^{89}$

More recently VEGF immunoreactivity has been correlated with increased vascular permeability to macromolecules, ${ }^{153}$ i.e. extravasated albumin in human diabetic retinae, and permeability appears to be increased in diabetic patients before the onset of clinically apparent retinopathy. ${ }^{143}$ It has been demonstrated that exogenous VEGF induces a fenestrated phenotype in endothelial cells of normally non-fenestrated dermal capillaries ${ }^{154}$ and that these changes can be inhibited by anti-VEGF monoclonal antibodies. In proliferative diabetic retinopathy VEGF is highly expressed in the vitreous and in the immediate vicinity of preretinal new vessels which are highly permeable to macromolecules and declines following panretinal laser photocoagulation. ${ }^{155,156}$ It is also likely that retinal-pigment-epithelial-generated VEGF sustains the fenestrated choriocapillaris necessary for the transport of vitamin A to the outer retina. Loss of retinal pigment epithelium cells and choroidal infiltration by glia can result in the contiguous choriocapillaris becoming non-fenestrated. ${ }^{157}$ Thus it seems that the retinal capillary endothelium can alter its phenotype according to local concentrations of VEGF.

\section{Endothelial dysfunction}

Increased vascular permeability in early diabetes probably represents an exaggeration of normal cell transport mechanisms and increased facility for fluid movement between intercellular tight junctions. ${ }^{158}$ 
Gardner et al. ${ }^{158}$ point out that histamine and VEGF increase vascular permeability, and reduce expression of one of the major endothelial junction zonula occludens proteins (ZO-1) allowing excess intercellular fluid leakage. ${ }^{134}$ Antihistamines have been shown to reduce the leakage of blood vessels in diabetic rats and clinical trials are under way to determine their effectiveness in exudative maculopathy. In more advanced diabetes the unrestricted passage of macromolecules indicates a serious failure of vascular endothelial function and may reflect a change in the structure and phenotype of those endothelial cells which have grossly thickened basement membranes and loss of pericytes. ${ }^{136}$

\section{Endocytosis}

Retinal vascular endothelial cells exposed to a high glucose medium $(25 \mathrm{mM})$ in culture show an increased uptake of tracer (HRP) from the medium by a pathological increase in the level of receptor-mediated endocytosis. Short-term diabetic animals also demonstrate a similar increased endocytosis in the retinal vasculature. ${ }^{159}$ This exaggerated endocytotic effect can be ameliorated by anti-glycation agents such as D-lysine and aminoguanidine, suggesting that the increased endocytosis is an attempt by the cell to replenish its plasma membrane components and receptors which are perceived by the cell as damaged or senescent due to glycation. ${ }^{160}$ It is conceivable that in diabetes, glycation of cell membranes interferes with normal plasma membrane recycling and receptormediated transport of macromolecules.

\section{Altered endothelial cell morphology: fenestrations}

The morphology and structure of vascular endothelial cells can be altered by haemodynamic forces, chronic inflammation, chemical mediators (histamines, prostaglandins) and growth factors IGF-1 and VEGF, with subsequent changes in form and permeability. In established diabetic retinopathy vascular endothelial cells can be grossly attenuated in areas of exudation and display increased intracytoplasmic vesicles and plasma membrane fenestrations. ${ }^{136}$ Incidentally retinal venules with grossly thickened basement membranes may also become fenestrated, possibly due to a dilution of barriermaintaining effects of the displaced paravascular glial cells. ${ }^{161}$ Retinal new vessels display no immunoreactivity for GLUT I, which is in keeping with their fenestrated endothelium, loss of selective permeability ${ }^{162}$ and lack of any imperative for facilitated glucose transport.

Once the retinal vascular endothelium loses its barrier functions other factors come into play. Accumulations of blood-borne proteins and lipids exert osmotic, oxidative and pro-inflammatory effects and altered storage of growth factor in the sclerotic basement membrane may have an exaggerated influence on a labile vascular endothelium.

\section{Structural changes}

\section{Basement membrane thickening}

Retinal vascular basement membranes not only provide structural support for the endothelial cells but also regulate cell adhesion, migration, differentiation and significantly influence proliferation. Retinal vascular basement membrane thickening is the first and most predictable histopathological change observed in human and experimental diabetes (Fig. 10). ${ }^{163}$ All vascular radicals are affected, particularly the microvasculature on the arterial side of the circulation, ${ }^{164}$ and measurable changes are present after only a few months of experimental diabetes. ${ }^{165}$ Increased synthesis of collagen IV, fibronectin and laminin by endothelial cells and pericytes under the influence of hyperglycaemia and AGEs adds to the bulk of the basement membrane. ${ }^{166-168}$ Furthermore advanced glycation of long-lived matrix proteins impedes their degradation by catabolic enzymes ${ }^{78}$ leading to a net increase in basement membrane thickness. ${ }^{75}$ In diabetes the thickened basement membrane becomes cross-linked, rigid and poorly compliant and may physically restrict capillary contraction and dilatation. Exaggeration of heparin sulphate proteoglycan synthesis also adds to the structural and biochemical complexity of the basement membrane affecting its ligation of key vasogenic, heparin-binding growth factors such as VEGF and bFGF. Extraneous endothelial cell and pericyte by-products and uncensored proteins from the circulation such as immunoglobulins and oxidised and/or glycated macromolecules may penetrate the increasingly permeable endothelium to become entrapped in the basement membrane complex, further complicating its chemistry and filtration role.

The thickened basement membrane may impede pericyte/endothelial cell contacts, interfere with cell signalling and diminish the inhibitory influence of pericytes on vascular endothelial cell proliferation. The separation of the vascular complex from neighbouring glial cells may also have consequences for endothelial cell structure and permeability ${ }^{136,157}$ Excess or abnormal

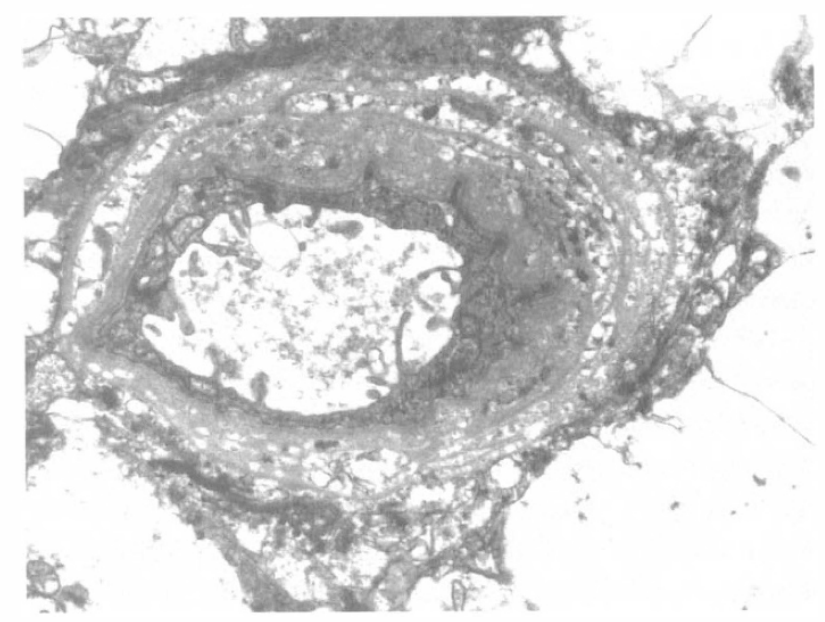

Fig. 10. Human diabetic retinal capillary demonstrating intact endothelium but grossly thickened basement membrane and absence of pericytes. 


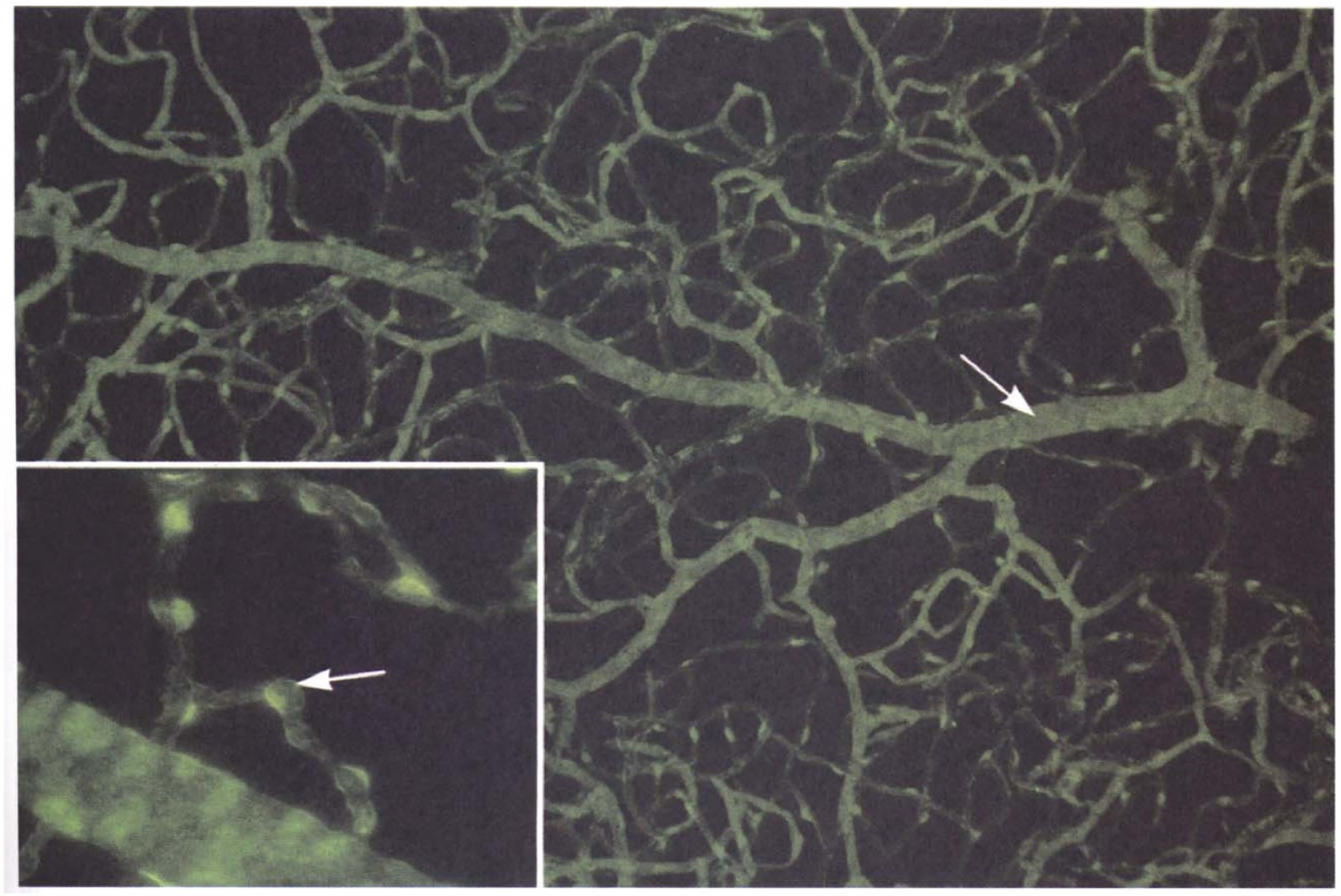

Fig. 11. Trypsin digest of the retinal microvasculature of a diabetic rat stained with antibodies to AGEs. There is striking immunoreactivity of smooth muscle cells and pericytes (arrows).

deposition of basement membrane proteins may also serve to disrupt the nature of complex cell-matrix interactions and influence their capability to spread, migrate and replicate. ${ }^{167}$ Oxidation, glycation and polyol pathway overactivity have been implicated in the pathogenesis of basement membrane thickening and ARIs and anti-glycation agents may prevent or moderate basement membrane thickening in experimental diabetic and galactosaemic animals. ${ }^{169}$

\section{Pericyte loss}

The premature and selective loss of pericytes is the cellular hallmark of diabetic retinopathy and probably represents a key event in deciding subsequent microvascular instability, decompensation and collapse. ${ }^{170,171}$ Pericyte loss is evident in human diabetes of about 10 years' duration, in diabetic dogs at 4-5 years and diabetic rats at 6-8 months (Fig. 10). The exact cause of pericyte demise is still unknown, but is probably the result of varied and cumulative biochemical insults coupled with the limited ability of the cell to repair and renew itself. Elevated glucose levels can directly inhibit pericyte cell growth ${ }^{25}$ and contraction ${ }^{120,127}$ and both hyperglycaemia and abrupt reduction in extracellular glucose can cause oxidative stress and induce apoptosis. $^{68}$

Sustained hyperactivity of the polyol pathway and subsequent metabolic disturbances may contribute to pericyte malfunction and death by aphysiological accumulations of sorbitol, pseudohypoxia and altered functions of key enzymes such as PKC and $\mathrm{Na}^{+} / \mathrm{K}^{+}$-ATPases. ARIs go some way to preserving pericytes in diabetic and galactosaemic animals and possibly prevent some of the later microvascular complications, although this remains controversial and may be influenced by the efficiency of the ARI used or the nature of the diabetic animal model. Clinical trials of ARIs launched on the basis of such experimental studies have not, thus far, shown that they prevent the onset of clinical diabetic retinopathy.

Pericytes may also be particularly susceptible to glycation. Pericytes express AGE receptors and Stitt et al..$^{80}$ have shown that after 8 weeks of diabetes in the

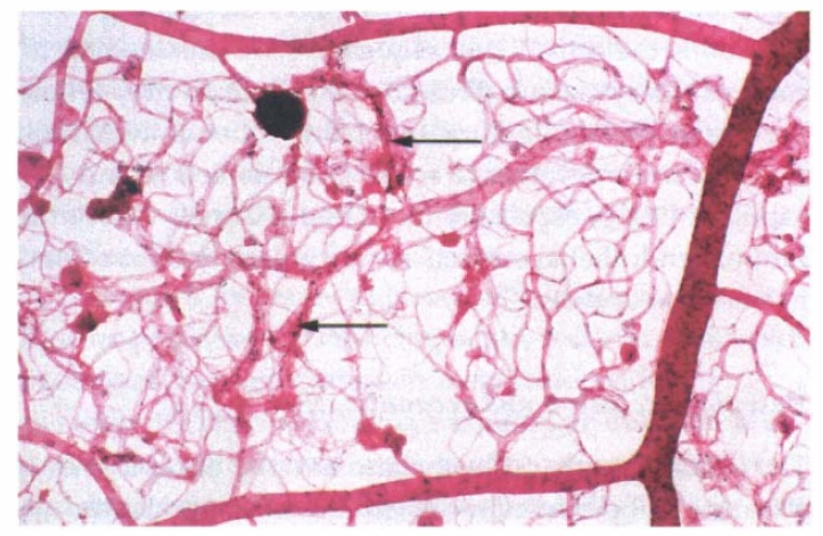

Fig. 12. Trypsin digest of human retina with background diabetic retinopathy shows smooth muscle cell loss in arterioles, microaneurysms, IRMAs (arrows) and acellular capillaries. 
rat there is a striking accumulation of intracytoplasmic AGEs, whereas endothelial cells display only modest concentrations (Fig. 11). ${ }^{80}$ Why AGEs should accumulate preferentially in pericytes is not known, although experimental studies have shown that AGEs have toxic effects on pericyte growth and function ${ }^{172}$ and antiglycation agents such as aminoguanidine prevent their loss in diabetic animals. ${ }^{173}$

Widespread pericyte loss will affect capillary tone and contraction and influence local blood flow control and possibly alter vascular permeability. Loss of pericyte/ endothelial cell contact may alter endothelial cell reactivity due to loss of the pericyte cell inhibitory influence through TGF- $\beta$. As pericytes are central to normal functioning of the capillary any pharmacological intervention to preserve them in diabetes would have a material effect on the development of later microvascular complications.

\section{Smooth muscle cell depletion}

Smooth muscle cell loss in retinal arterioles occurs about the same time as pericyte death in diabetic dogs and has also been noted in human retina (Fig. 12). Smooth muscle cell depletion has also been overshadowed by the more discernible pericyte loss and has only recently been highlighted by Gardiner et al. ${ }^{16}$ Smooth muscle cell loss in pre-capillary arterioles has major implications for autoregulation of the downstream capillary bed and endothelial cell permeability and survival. Loss of smooth muscle cells and pericytes is probably linked as both cell types demonstrate high polyol pathway activity under conditions of hyperglycaemia and respond biochemically to ARIs. In common with pericytes, arteriolar smooth muscle cells have been shown to bear AGE receptors and accumulate these adducts in diabetes or after exposure of non-diabetic animals to exogenous AGE-modified albumin. ${ }^{80}$

\section{Vascular endothelial cell loss}

The cause of early endothelial cell failure is ill understood, although loss of integrity of the vascular endothelium with platelet deposition on the exposed basement membrane and activation of the clotting cascade is the most likely sequence of events leading to early capillary closure. Endothelial cell death may follow inexorable metabolic duress or failure of endothelial cell division and migration to make good defects in the capillary lining, especially in dilated channels where the luminal endothelial surface area is greatly increased and in microaneurysms. ${ }^{174}$

\section{Vascular occlusion and recanalisation}

The insidious early occlusion and atrophy of capillaries is a feature of both insulin-dependent and non-insulindependent diabetes and is observed in human diabetics and galactosaemic/diabetic animals in the absence of retinopathy. ${ }^{175}$ The natural course of vascular occlusion in diabetics is unpredictable and varies from subtle and inconsequential capillary fallout to inexorable and severe collapse of the microvasculature and the subsequent sequelae of an ischaemic retina. The exact cause of capillary occlusion is still not known, although there are numerous precipitating factors including haemodynamic stress, endothelial cell loss and reduction of intraluminal pressure below the capillary critical closing pressure.

Altered local coagulability of blood in tandem with upregulation of adhesion molecules and leucocyte activation may also precipitate capillary occlusion and fibrin locking of juxtaposed endothelial cells. ${ }^{95,98,176}$ Such a scenario usually presents in advanced or end-stage diabetic retinopathy where there is severe circulatory stasis and damaged neuropile. Inflammatory cells, particularly monocytes and neutrophils, are consistently present in retinal microaneurysms and recanalised vessels. ${ }^{174}$

Acellular and occluded capillaries (and larger vessels) persist as redundant, non-functional basement membrane tubes, and have been labelled 'ghost vessels'; however, some defunct channels are re-endothelialised and may become serviceable if connections are achieved with a viable circulation (Fig. 12). These channels generally traverse ischaemic inner retina and may be associated with increased VEGF levels. Most refurbished capillaries have a high complement of inflammatory cells (especially macrophages) and these are the likely source of angiogenic growth factors.

\section{Neovascularisation}

Ischaemic and putatively hypoxic retina is a strong stimulus for intra- and extraretinal neovascularisation. ${ }^{176}$ Intraretinal neovascularisation is usually a muted reponse and is clinically manifest as IRMAs. It is often difficult to decide clinically whether IRMAs are de novo new vessels en route to extraretinal neovascularisation or occluded capillaries which have re-endothelialised

(Fig. 12). Most new or reconstituted intraretinal vessels have a continuous 'tight' endothelium with permeability characteristics more reminiscent of normal vessels than new preretinal vessels. Whether they are functionally provident is not known.

Most classical new retinal vessels originate from veins or venules and rapidly access the preretinal space where their future development is determined by the physical constitution of glycated vitreous and the preretinal concentration of various growth factors. ${ }^{177,178}$ Activated vascular endothelial cells dissolve their own basement membrane and proliferate as tubes of loosely connected organelle-rich endothelial cells under the instruction of various angiogenic growth factors. Endothelial cells at the growing front of vascular sprouts have few pericyte contacts (Fig. 8B) but interact with appropriate receptors to extracellular matrix components such as laminin on the freshly elaborated basement membrane. One study has recently demonstrated expression of the $67 \mathrm{kDa}$ laminin receptor (67LR) by proliferating retinal vascular endothelial cells with the quiescent, normal intraretinal 
vessels showing little or no expression. ${ }^{179}$ Hammes et al. ${ }^{180}$ have also shown that specific integrin receptors are crucial in the development of new vessels and that antagonists directed against integrin receptors can alter the angiogenic response. ${ }^{181}$

The required cocktail of growth factors to induce and sustain intra- and preretinal neovascularisation is being intensively investigated, although VEGF is rapidly assuming primacy as the key angiogenic factor. ${ }^{91,182,183}$ VEGF is hypoxia-sensitive and the peptide expression is elevated in the vicinity of new vessel complexes. VEGF levels are also elevated in the vitreous of patients with preretinal neovascularisation and in the aqueous of individuals with neovascular glaucoma. ${ }^{183,184}$ The putative role of other members of the VEGF family is a growing area of interest, since VEGF-B,C,D and placental growth factor share structural and functional homology with VEGF itself. Indeed, basic and acidic FGF, ${ }^{185-187}$ PDGF, EGF, IGF- $1,{ }^{76,188}$ TGF- $\beta{ }^{189}$ hepatocyte growth factor and a variety of interleukins must all be included in the angiogenic equation. ${ }^{190}$ IGF-1 has been highlighted as a key culprit in exacerbating neovascularisation in those poorly controlled diabetics, entering strict glucose control regimens (normoglycaemic re-entry

phenomenon).

The natural course of preretinal new vessels tends to be cyclical, progressing from rapidly advancing fronds to established vascular complexes with competent feeding channels and ultimately to atrophic acellular strands with high complements of supporting collagen and glial tissue. In end-stage disease the balance of growth factors has changed decisively in favour of growth inhibitors such as TGF- $\beta$. There is a constant interplay of growth factor effects at the outer retina and preretinal space, even in patients with no diabetic retinopathy. Mitchell et al. ${ }^{191}$ have shown that some $10 \%$ of diabetic patients with no retinopathy develop clinically detectable preretinal membranes subsequent to the proliferation of fibroblasts and glial cells. Opportunities for biochemical manipulation of retinal neovascularisation are fast becoming a reality if not a practical proposition.

\section{Therapeutic options}

\section{Prevention of retinopathy}

Maintaining euglycaemia

The objective in potentially diabetic patients is to anticipate and abort the disease process. In type I diabetics the auto-immune disease process that leads to the destruction of insulin-secreting pancreatic islet $\beta$ cells may be tempered or abated by early insulin treatment. ${ }^{192}$ Nicotinamide and immunosuppressive therapy may salvage functioning $\beta$ cells and induce remission or delay in the onset of diabetes in antibody-positive children. ${ }^{193}$ Nevertheless, most current opinion holds that potentially toxic therapy should only be offered where the onset of diabetes can be predicted with 'near certainty' and the search for predictive clues, such as presence of insulin antibodies and genetic markers, proceeds apace. Some predictive models offer a $90 \%$ probability of positive individuals progressing to insulin therapy within 3 years and suggest that the remaining $10 \%$ of patients will almost certainly follow the same route with time. ${ }^{194}$ In type II diabetics, in whom there is only a relative tissue insulin deficit, prevention is largely directed at reducing insulin requirements (e.g. controlling obesity) and increasing insulin sensitivity at the receptor level in patients with a genetic predisposition to the disease process.

\section{Re-establishing euglycaemia}

In established diabetics the early, complete and permanent restoration of euglycaemia is the best guarantee that retinopathy will not develop. Pancreatic transplantation is now a practical proposition for insulindependent diabetics, but requires long-term immunosuppression and at present this procedure is the preserve of specialised centres and is generally offered only to diabetics with advanced disease and secondary complications such as end-stage nephropathy. ${ }^{195,196}$ Even where euglycaemia is achieved there is little recovery of entrenched retinopathy or visual gain. ${ }^{197-199}$ Islet cell transplantation with portal seeding of purified $\beta$ cells is also feasible and less invasive, and in a few patients satisfies all their insulin needs. Nevertheless, life-long immunosuppressive therapy is still mandatory and the harvesting of sufficient numbers of pure and functioning cells to establish euglycaemia presents special logistical problems. $^{200}$

\section{Achieving 'near' euglycaemia}

For most diabetics at this time the immediate goal is to achieve near euglycaemia and moderate those risk factors which may potentiate or aggravate vascular disease, such as hypertension, ${ }^{35,201}$ smoking, hyperlipidaemia and anaemia. ${ }^{9}$ The advantages of good and long-term diabetic control have been highlighted by recent and exhaustive trials for both insulin-dependent ${ }^{33}$ and non-insulin-dependent diabetics, ${ }^{10,201}$ and the introduction of new insulins, novel administrative techniques and improved programmes of care are helping to achieve this objective. For type II diabetics other therapeutic avenues exist to ameliorate but not cure hyperglycaemia, such as reducing gastrointestinal glucose absorption and utilisation. Clinical diabetes may also be improved by increasing insulin sensitivity, improving $\beta$ cell function at a cellular level or moderating insulin need by weight reduction and exercise. $^{202}$

The quest for near euglycaemia, although laudable, has the potential for inducing acute, recurrent and even prolonged hypoglycaemia in insulin-dependent diabetics. ${ }^{203}$ Hypoglycaemia may trigger the release of potent vasoconstrictors such as adrenaline, vasopressin and angiotensin II, alter blood coagulability and viscosity and activate neutrophils with the combined effect of damaging capillary endothelium, inducing capillary closure and exaggerating proliferative retinopathy. 


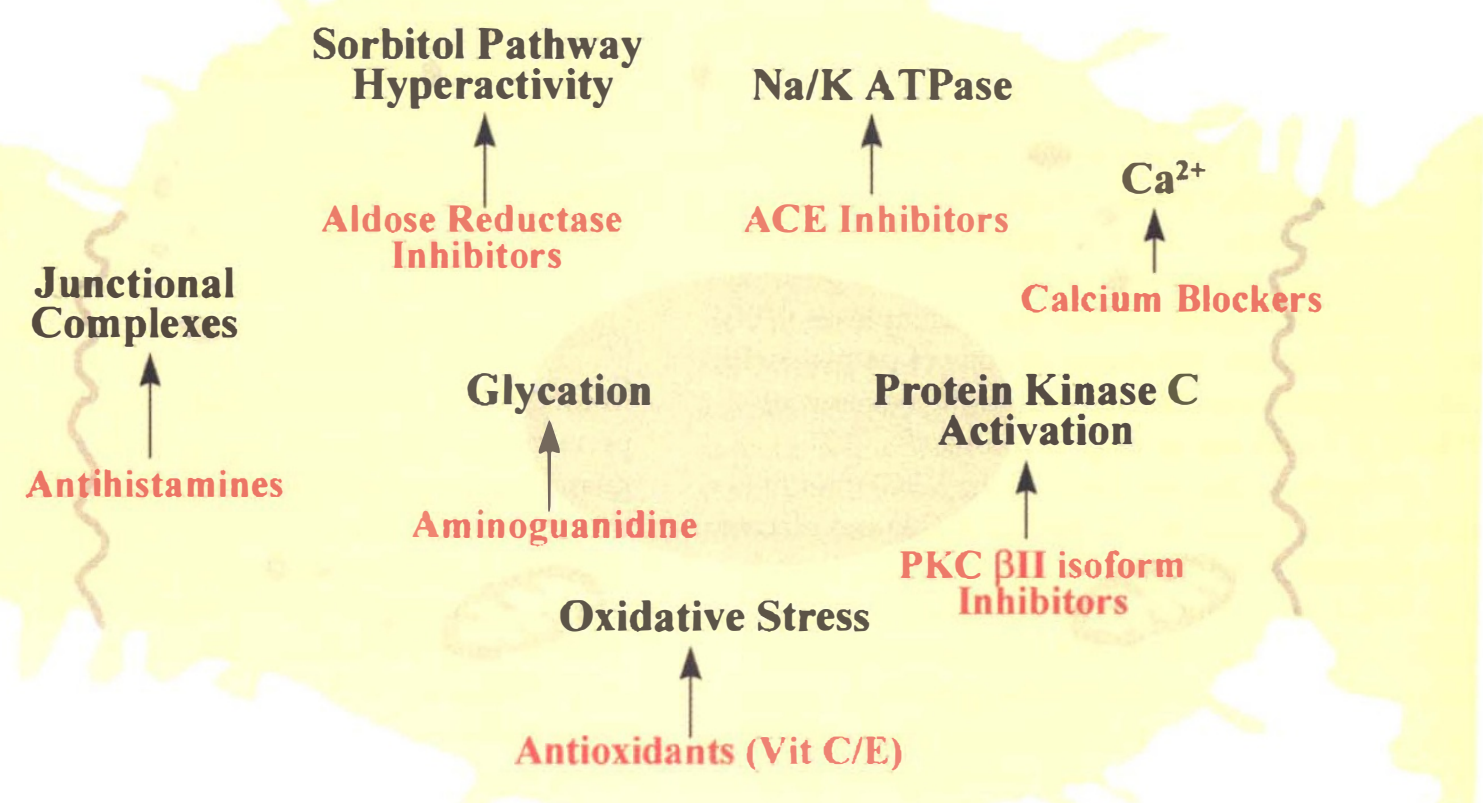

Fig. 13. Therapeutic strategies under investigation to prevent/ameliorate diabetic retinopathy.

Relative 'hypoglycaemia' following acute normalisation of blood glucose levels in ill-controlled diabetics (re-entry phenomenon) may cause sudden intensification of an ischaemic retinopathy and has been attributed in part to increased IGF-1 levels. It is important to monitor the retinopathic progress carefully in such patients and if necessary to undertake a preemptive strike with laser photocoagulation in patients with pre-proliferative or early proliferative retinopathy.

\section{Limiting adverse biochemical processes}

In the absence of a cure for diabetes, or guaranteed euglycaemia, the best prospect for preventing retinopathy or extending the time to presentation lies with the correction or moderation of those biochemical processes which lead to retinal vasculopathy (Fig. 13). The better understanding of hyperglycaemia-linked biochemical processes which damage vascular cells and the parallel development of pharmacological agents to prevent or limit such reactions now presents an unprecedented opportunity to make some impact on the pre-retinopathic disease process in diabetes. It has been demonstrated in established diabetic or galactosaemic animals that development or progression of retinopathy can occur despite normalisation of glycaemic control ${ }^{204}$ or withdrawal of galactosaemic diet, ${ }^{205}$ so early institution of effective therapy seems crucial in stemming the microvascular disease process. ${ }^{206}$

As only a proportion of diabetics develop sightthreatening retinopathy and some of the putative antiretinopathic drugs have known or potential side-effects, there is now a clear imperative to identify those diabetics likely to proceed to significant retinopathy, before irreversible changes have occurred to vascular cells. Apart from insulin and oral hypoglycaemic agents no drugs to date have shown an unequivocal and durable effect in preventing, stabilising or reversing diabetic retinopathy. Some pharmacological preparations, however, hold promise for correcting abnormal metabolic functions at a tissue culture and experimental animal level and some preparations are currently being assessed in clinical trials. Other potential therapeutic agents are at a conceptual level but hold exciting possibilities for the future.

Anti-oxidants. The exaggerated oxidative processes in diabetes, coupled with a reduction in anti-oxidants, would suggest that dietary supplementation with antioxidants might be helpful. It has been shown that vitamins $C$ and $E$ reduce concentrations of oxidised low density lipoproteins (LDLs) and increase NO production with favourable effects on retinal blood flow, and coincidentally on any existing hypertension. ${ }^{207}$ Vitamin $\mathrm{E}$, in addition to its anti-oxidant properties, inhibits the changes in DAG level and PKC- $\beta$ II activation induced by high glucose in cultured cells. ${ }^{208}$ Vitamin E supplements in diabetic rats can also prevent abnormalities in retinal blood flow. ${ }^{209}$ It has also been proposed that $\alpha$-lipoic acid might improve retinal haemodynamics; however, despite the compelling logic of vitamin therapy there is no clear evidence that supplements favourably influence the course of diabetic retinopathy. One recent epidemiological study reported that no protective effect was observed with anti-oxidant nutrients vitamins $\mathrm{C}, \mathrm{E}$ and $\beta$-carotene, ${ }^{71}$ although in interpreting these findings 
it should be noted that $\beta$-carotene is not an anti-oxidant and that vitamin $C$ may be pro-oxidant in some situations.

Aldose reductase inhibitors. The recognition that polyol pathway overactivity produces adverse biochemical reactions in retinal vascular cells led to the use of ARIs to forestall the development of diabetic retinopathy. ARIs diminish basement membrane thickening and conserve pericytes in the retinal microvasculature of some diabetic and galactosaemic animals, especially in galactosaemic models where retinal galacticol concentrations are particularly high ${ }^{210}$ (galacticol is not metabolised further by polyol dehydrogenase, in contrast to sorbitol); however, Engerman and Kern ${ }^{48}$ found that the ARI sorbinil did not significantly influence the development of retinopathy in either diabetic or galactosaemic dogs.

The ARI-509 prevents expression of VEGF in galactosaemic rats ${ }^{211}$ and some early clinical studies reported that ARIs improve capillary permeability in non-retinopathic diabetics, ${ }^{212}$ but to date no randomised control trial has shown that these drugs have any observed clinical effect on the onset of diabetic retinopathy. ${ }^{47}$ Frank $^{213}$ and others have highlighted the fact that ARI trials have not been initiated at or near the time of diagnosis of diabetes and that many patients may have irreversible structural changes already present in the retina which do not yield to ARI therapy.

ARIs can slow, but not reverse, the progression of diabetic polyneuropathy and autonomic neuropathy and some workers believe that their failure to influence diabetic retinopathy may reflect the nature and concentration of the inhibitor used and length of time of the trial and that differently constructed trials may demonstrate a therapeutic benefit. ${ }^{55}$

Protein kinase C- $\beta$ II blockade. PKC- $\beta$ II is involved in modulation of VEGF receptor signal transduction cascade and the specific inhibition of this isoform is able to prevent the proliferation of endothelial cells induced by VEGF. PKC- $\beta$ II activation can affect a wide range of vascular functions in diabetics, including permeability, coagulation and blood flow. Recent evidence that specific blockage of PKC- $\beta$ II using LY333531 can reverse abnormal haemodynamics in diabetic animals raises the possibility of influencing the disease process at a preretinopathic stage. ${ }^{56,60}$ LY333531 can also decrease new vessel formation in pigs with experimental branch retinal vein thrombosis. ${ }^{214}$ PKC- $\beta I I$ inhibition seems to have few adverse side-effects and clinical studies are under way to establish its effectiveness.

Anti-glycation agents. Glycational processes culminating in the intra- and extracellular accumulation of reactive end-products and cross-linked proteins can affect the form and function of vascular cells and their extracellular matrices in established diabetes. There is a positive relationship between the incidence and progression of diabetic retinopathy and levels of $\mathrm{HbA}_{1 \mathrm{C}}$ and it has been demonstrated that some of the pathological glycational processes can be prevented or minimised by antiglycation drugs in diabetic animal models, ${ }^{160,173,215,216}$ suggesting therapeutic applications in the clinical setting. Anti-glycation agents such as aminoguanidine may also inhibit NO synthesis and reduce dysfunction induced by elevated NO levels in diabetes, ${ }^{217}$ and Stitt et al. ${ }^{178}$ have used aminoguanidine to reverse vitreous cross-linking mediated by AGEs.

Aminoguanidine, the best-characterised antiglycation agent, improves peripheral nerve and retinal electroretinographic function in experimental diabetic animals and reduces basement membrane thickening and pericyte dropout, ${ }^{173,180}$ and is now the subject of phase III clinical trials in diabetic patients. Other antiglycation agents are currently under development; however, there are still unanswered questions about the best time of such intervention in the retinopathic process, optimum dosage, appropriate patients and whether functional benefits outweigh any long-term toxic reactions or adverse effects.

Recently formulated 'AGE-breakers' have proved effective at a molecular level in preventing cross-linking of glycated proteins. Whether any of these novel drugs will prove effective in treating patients is not known but is a consideration for the future. ${ }^{216}$

\section{Angiotensin converting enzyme (ACE) inhibitors, calcium} channel blockers, anti-coagulants, antihistamines and aspirin. It has been reported that certain angiotensin I-converting enzymes (ACE) inhibitors, such as captopril, are protective against retinopathy, nephropathy and neuropathy in insulin-dependent diabetic patients, irrespective of the presence of hypertension and that they can improve microvascular complications and delay or reverse diabetic retinopathy. ${ }^{218}$ The mode of such putative action is still unclear; however, some studies demonstrate a restoration of depressed $\mathrm{Na}^{+} / \mathrm{K}^{+}$-ATPase levels in diabetic animals to normal. ${ }^{53,219}$ Improved blood flow may reflect reduced ACE activity or increased bradykinin levels with associated formation of NO. ${ }^{220}$ It is also speculated that calcium-channel blockade may improve retinal vascular dysfunction in diabetics by improving vascular permeability and possibly countering vascular occlusion by modulating smooth muscle contraction. ${ }^{221}$ The control of hypertension by both ACE inhibitors and calcium blockers should also have a favourable effect on the development of diabetic retinopathy. It would be anticipated that aspirin with its anti-coagulant effects should improve the natural course of diabetic retinopathy, especially in the face of capillary occlusion and thrombosis. However, the ETDRS ${ }^{222}$ did not find any beneficial effects of aspirin $(650 \mathrm{mg} /$ day $)$ in retarding the progression of pre-proliferative or early proliferative retinopathy or macular oedema.

Alternatively, aspirin did not worsen the risk of vitreous haemorrhage in relatively advanced diabetic retinopathy. Whether early intervention with aspirin retards the development of early retinopathy or minimises capillary fallout is not known. 
Histamine reduces the expression of $\mathrm{ZO}-1$, a major tight junction protein of vascular endothelial cells, and increases vascular permeability. In preliminary studies in humans antihistamines increase barrier functions. ${ }^{223}$ Antihistamines are now being tested in view of their putative positive effect on retinal vascular permeability.

\section{Management of vascular complications}

\section{Exudation: oedema}

The pharmacological reversal of microvascular incompetence, especially macular oedema, would be a signal advance in the management of diabetic patients as the current established treatment of laser

photocoagulation is both destructive and of doubtful use in ischaemic and cystoid macular oedema. There is now growing evidence that increased concentrations and altered balance of certain growth factors can alter vascular permeability and that regulation of expression, secretion and target cell receptors may improve permeability and vascular function. Suppression of VEGF activity by antibodies and PKC- $\beta I I$ isoform inhibitors can enhance barrier functions in experimental diabetes $^{224}$ and microvascular incompetence induced by intravitreal injection of IGF-1 can also be abolished by neutralising pharmacological actions. New techniques are becoming available whereby therapeutic agents, such as biodegradable polymers containing co-drugs (e.g. fluorouracil), ${ }^{225,226}$ can be introduced into the vitreous cavity to control cell growth in experimental animals and it is only a matter of time before acceptable anti-VEGF agents become available for therapeutic evaluation. When considering such an approach it must be remembered that VEGF is a potent survival factor ${ }^{152}$ and inhibition or attenuation of its production in a severely compromised retinal vasculature could have adverse effects.

\section{Vascular occlusion: revascularisation}

In diabetics, vascular occlusion tends to be insidious, progressive and irreversible. Some re-endothelialisation and recanalisation of defunct channels does occur and limited intraretinal neovascularisation may take place, but return of function to ischaemic retina is insignificant and the use of neuroprotective agents, such as nerve growth factor, $^{227}$ even if feasible, is unlikely to make a material difference to survival of neurones and vision. It has recently been shown that acidic and basic fibroblastic growth factors (aFGF, bFGF) injected into the ischaemic myocardium of patients with ischaemic heart disease can revascularise the impoverished tissue and improve cardiac functions. ${ }^{228}$ It is possible that limited reperfusion of ischaemic retina may be achieved with receptor analogues and/or growth factors that aid survival of vascular cells, facilitate their replication and migration or improve their interaction with substrates, especially defunct basement membrane tubes. The challenge now is to encourage by pharmacological means the recanalisation of defunct and acellular capillary beds and establish a viable circulation without the process extending to the formation of preretinal new vessels.

\section{Neovascularisation}

The development of retinal neovascularisation in diabetes is a poor prognostic sign for vision and retinal integrity and an important indication for panretinal photocoagulation. The ability to prevent and manipulate new vessel growth would not only improve the survival of the retina and avoid laser-induced atrophy of the neuropile, but in a wider biological sense have important implications for the treatment of cancerous lesions which are dependent on a blood supply.

VEGF is now the focus of most experimental therapies aimed at inhibiting ocular neovascularisation ${ }^{229,230}$ and preretinal neovascularisation in the hyperoxia-treated mouse model can be suppressed by intravitreal injection of VEGF antisense oligonucleotides. ${ }^{231}$ It has also been shown that VEGF levels fall dramatically in the vitreous following panretinal laser photocoagulation for proliferative diabetic retinopathy. ${ }^{156}$ Vitreous b-FGF levels are also raised in proliferative diabetic retinopathy and it may be that the angiogenic potential of VEGF acts synergystically with b-FGF or other angiogenic growth factors. $^{232}$

Other anti-angiogenic preparations are also being tested; for example, intravitreal sustained-release TA/5FU co-drug effectively inhibits the progression of proliferative vitreal retinopathy in rabbit models that mimic human disease. ${ }^{226}$ The use of various inhibitors of vascular endothelial cell growth, including somatostatin (which inhibits growth hormone), thalidomide and TGF- $\beta$, are also under scrutiny. Because so many growth factors, cytokines and adhesion molecules act in concert to promote or contain neovascularisation, the biochemical control of vasoproliferation in diabetics is a monumental task. It also has to be remembered that many of the above-mentioned growth factors have key roles in sustaining and protecting retinal vascular cells and their manipulation may have important or as yet unseen negative effects.

The vitreous may act as a scaffold for preretinal vessels and disruption of the vitreo-retinal interface may deny neovascular fronds attachment opportunities. With this in mind Sebag ${ }^{233}$ has developed a pharmacological vitreolysis approach using hyaluronidase digestion of the posterior vitreous cortex to induce posterior vitreous detachment at the site of new vessel growth. This may represent a novel and exciting approach to prevent neovascularisation in susceptible patients and perhaps prevent fibrotic retinal detachments.

\section{Conclusion}

The entire retina is affected in some way or other by long-standing diabetes; however, changes in the photoreceptors and neuropile are mild, rarely threaten the survival of the cell and are generally inconsequential 
as far as day-to-day visual functions are concerned. The retinal microvasculature is the prime casualty of the diabetic process as its component cells experience the wear and tear of a hyperdynamic retinal circulation. These cells are also vulnerable to oxidative and glycation-related stress and become susceptible to biochemical and growth factor aberrations induced by prolonged hyperglycaemia.

Thickening of vascular basement membranes in diabetes serves to immobilise capillaries and isolate the component cells from each other and their supporting glia. This abnormal thickening may impede the normal cellular communications which moderate and influence migration, replication and continued survival of cells. Pericyte death is the key cellular event which coincides with vascular instability and eventual demise of affected capillary units. Its preferential susceptibility in diabetics is a unique and enigmatic event and may reflect pericyte sensitivity to glycation and oxidation, poor replicative capacity and possibly the ease with which this cell can be directed to apoptosis. Capillary occlusion and neovascularisation are the inescapable consequences of a failed circulation and grossly disordered metabolic events in the nearby tissues of supply.

Although the key to management of diabetic complications is optimal control of the metabolic disorder, aphysiological hyperglycaemia will always occur and prolonged overcommitment of the glycolytic and associated catabolic pathways has the potential to threaten survival of the retinal vascular cells. The recent identification and characterisation of biochemical abnormalities in vascular cells induced by hyperglycaemia has provided some hope for early therapeutic intervention. Our enhanced understanding of retinal blood flow, vasopermeability and neovascularisation also offer some prospect of treating downstream complications by the judicious modulation of growth factors and biochemical blockade of those metabolic processes which yield gratuitous and injurious end-products.

Optimisation of diabetic control, early correction of metabolic abnormalities in retinal vascular cells and a pre-emptive strike to limit or reverse vascular occlusion, impaired retinal permeability and neovascularisation are the challenges for the future and given some success it should be possible to significantly extend the functional life of the retinal circulation and guarantee a life-time of serviceable vision in most if not all diabetics.

I would like to record my special thanks to Dr T. A. Gardiner and Dr A. W. Stitt for their contribution toward this paper and Miss E. Latimer for preparing the manuscript. I also acknowledge support from the Trust for the Visually Impaired (N. Ireland).

\section{References}

1. Sanders MD. The Bowman lecture. Papilloedema: 'The pendulum of progress'. Eye 1997;11:267-94.
2. Burdon-Sanderson J, Hulke JW. The collected papers of Sir W Bowman, Bart, FRS, vol 1. London: Harrison and Sons, 1892:97-128.

3. Bliss M. The discovery of insulin. Toronto: McClelland \& Stewart, 1996.

4. MacKenzie S. A case of glycosuric retinitis with comments. R Lond Ophthalmic Hosp Rep 1879;9:134-57.

5. Nettleship E. Chronic retinitis with formation of blood vessels in the vitreous in a patient with diabetes. One eye lost by results of chronic iritis accompanied by the formation of large vessels in the iris. Trans Ophthalmol Soc UK 1888;8:159-61.

6. Klein R, Klein BEK, Moss SE, Davis MD, DeMets DL. The Wisconsin Epidemiological Study of Diabetic Retinopathy. II. Prevalence and risk of diabetic retinopathy when age at diagnosis is less than 30 years. Arch Ophthalmol 1984;102:520-6.

7. Klein R, Klein BEK, Moss SE, Davis MD, DeMets DL. The Wisconsin Epidemiological Study of Diabetic Retinopathy. III. Prevalence and risk of diabetic retinopathy when age at diagnosis is 30 or more years. Arch Ophthalmol 1984;102:527-32.

8. Evans J, Rooney C, Ashwood F, Dattani N, Wormald R. Blindness and partial sight in England and Wales: April 1990-March 1991. Health Trends 1996;28:5-12.

9. Early Treatment Diabetic Retinopathy Study Report no. 18 Risk factors for high-risk proliferative diabetic retinopathy and severe visual loss. Invest Ophthalmol Vis Sci 1998;39:233-52.

10. Köhner EM, Aldington SJ, Stratton IM, Manley SE, Holman RR, Matthews DR, Turner RC. United Kingdom Prospective Diabetes Study no. 30. Arch Ophthalmol 1998;116:297-303.

11. Gardner TW, Lieth E, Khin SA, Barber AJ, Bonsall DJ, Lesher $\mathrm{T}$, et al. Astrocytes increase barrier properties and ZO-1 expression in retinal vascular endothelial cells. Invest Ophthalmol Vis Sci 1997;38:2423-7.

12. Janzer RC, Raff MC. Astrocytes induce blood-brain barrier properties in endothelial cells. Nature 1987;325:253-7.

13. Larson DM, Carson MP, Haudenschild CC. Junctional transfer of small molecules in cultured bovine brain microvascular endothelial cells and pericytes. Microvasc Res 1987;34:184-99.

14. Mandarino LJ. Current hypotheses for the biochemical basis of diabetic retinopathy. Diabetes Care 1992;15:1892-901.

15. Roufail E, Stringer M, Rees S. Nitric oxide synthase immunoreactivity and NADPH diaphorase staining are colocalised in neurons closely associated with the vasculature in rat and human retina. Brain Res 1995;684:36-46.

16. Gardiner TA, Stitt AW, Anderson HR, Archer DB. Selective loss of vascular smooth muscle cells in the retinal microcirculation of diabetic dogs. Br J Ophthalmol 1994;78:54-60.

17. Folkman J, Klagsbrun M, Sasse J, Wadzinski M, Ingber D, Vlodavsky J. A heparin-binding angiogenic protein - basic fibroblastic growth factor - is stored within basement membrane. Am J Pathol 1988;130:393-400.

18. Stehouwer CDA, Lambert J, Donker AJM, Van Hinsbergh VWM. Endothelial dysfunction and pathogenesis of diabetic angiopathy. Cardiovasc Res 1997;34:55-68.

19. Koedam JA, Cramer EM, Briend E, Furie B, Furie BC, Wagner DD. P-selectin, a granule membrane protein of platelets and endothelial cells, follows the regulated secretory pathway in AtT-20 cells. J Cell Biol 1992;116:617-25.

20. Sharma NK, Gardiner TA, Archer DB. A morphologic and autoradiographic study of cell death and regeneration in the retinal microvasculature of normal and diabetic rats. Am J Ophthalmol 1985;100:51-60.

21. Chen $\mathrm{Q}$, Anderson DR. Effect of $\mathrm{CO}_{2}$ on intracellular $\mathrm{pH}$ and contraction of retinal capillary pericytes. Invest Ophthalmol Vis Sci 1997;38:643-51. 
22. Haefliger IO, Zschauer A, Anderson DR. Relaxation of retinal pericyte contractile tone through the nitric oxide-cyclic guanosine monophosphate pathway. Invest Ophthalmol Vis Sci 1994;35:991-7.

23. Haefliger IO, Meyer P, Flammer J, Lüscher TF. The vascular endothelium as a regulator of the ocular circulation: a new concept in ophthalmology. Surv Ophthalmol 1994;39:123-32.

24. Orlidge A, D'Amore PA. Inhibition of capillary endothelial cell growth by pericytes and smooth muscle cells. J Cell Biol 1987;105:1455-62.

25. Antonelli-Orlidge A, Saunders KB, Smith SR, D'Amore PA. An activated form of transforming growth factor $\beta$ is produced by co-cultures of endothelial cells and pericytes. Proc Natl Acad Sci USA 1989;86:4544-8.

26. Ikeda T, Homma Y, Nisida K, Hirase K, Sotozono C, Kinoshita $S$, et al. Expression of transforming growth factorbetas and their receptors by human retinal glial cells. Curr Eye Res 1998;17:546-50.

27. Amin RH, Frank RN, Kennedy A, Eliot D, Puklin JE, Abrams GW. Vascular endothelial growth factor is present in glial cells of the retina and optic nerve of human subjects with non-proliferative diabetic retinopathy. Invest Ophthalmol Vis Sci 1997;38:36-47.

28. Zhang Y, Stone J. Role of astrocytes in the control of developing retinal vessels. Invest Ophthalmol Vis Sci 1997;38:1653-66.

29. Gerhardinger C, Brown LF, Roy S, Mizutani M, Zucker CL, Lorenzi M. Expression of vascular endothelial growth factor in the human retina and in non-proliferative diabetic retinopathy. Am J Pathol 1998;152:1453-62.

30. Hammes HP, Lin J, Bretzel RG, Brownlee M, Breier G. Upregulation of the vascular endothelial growth factor/ vascular endothelial growth factor receptor system in experimental background diabetic retinopathy of the rat. Diabetes 1998;47:401-6.

31. Sone H, Kawakami Y, Okuda Y, Sekine Y, Honmura S, Matsuo $\mathrm{K}$, et al. Ocular vascular endothelial growth factor levels in diabetic rats are elevated before observable retinal proliferative changes. Diabetologia 1997;40:726-30.

32. Barber AJ, Lieth E, Khin SA, Antonetti DA, Buchanan AG, Gardner TW. Neural apoptosis in the retina during experimental and human diabetes: early onset and effect of insulin. J Clin Invest 1998;102:783-91.

33. The Diabetes Control and Complications Trial Research Group. The effect of intensive treatment of diabetes on the development and progression of long-term complications in insulin-dependent diabetes mellitus. N Engl J Med 1993;329:977-86.

34. The Diabetes Control and Complications Trial. The effect of intensive diabetes treatment on the progression of diabetic retinopathy in insulin-dependent diabetes mellitus. Arch Ophthalmol 1995;113:35-51.

35. UK Prospective Diabetes Study Group. Tight blood pressure control and risk of macrovascular and microvascular complications in type 2 diabetes. UK PDS 38. BMJ 1998;317:703-13.

36. Thorens B, Charron MJ, Lodish HF. Molecular physiology of glucose transporters. Diabetes Care 1990;13:209-18.

37. Mandarino LJ, Finlayson J, Hassell JR. High glucose downregulates glucose transport activity in retinal capillary pericytes but not endothelial cells. Invest Ophthalmol Vis Sci 1994;35:964-72.

38. Knott RM, Muckersie E, Robertson M, Forrester JV. Glucose-dependent regulation of DNA synthesis in bovine retinal endothelial cells. Curr Eye Res 1998;17:1-8.

39. Knott RM, Forrester JV. Role of glucose regulatory mechanisms in diabetic retinopathy. Br J Ophthalmol 1995;79:1046-9.
40. Berweck S, Thieme H, Lepple-Wienhues A, Helbig H, Wiederholt $\mathrm{M}$. Insulin-induced hyperpolarisation in retinal capillary pericytes. Invest Ophthalmol Vis Sci 1993;34:3402-7.

41. Rungger-Brändle E, Kolb H, Niemeyer G. Histochemical demonstration of glycogen in neurons of the cat retina. Invest Ophthalmol Vis Sci 1996;37:702-15.

42. Sosula L, Beaumont P, Hollows FC, Jonson KM, Regtop HL. Glycogen accumulation in the retinal neurons and glial cells of streptozotocin-diabetic rats: quantitative electron microscopy. Diabetes 1974;23:221-31.

43. Greene DA, Lattimer SA, Sima AAF. Sorbitol, phosphoinositides and sodium-potassium ATPase in the pathogenesis of diabetic complications. N Engl J Med 1987;316:599-606.

44. Williamson JR, Chang K, Frangos M, Hasan KS, Ido Y, Kawamura T, et al. Hyperglycemic pseudohypoxia and diabetic complications. Diabetes 1993;42:801-13.

45. Tilton RG, Kawamura T, Chang KC, Ido Y, Bjercke RJ, Stephan CC, et al. Vascular dysfunction induced by elevated glucose levels in rats is mediated by vascular endothelial growth factor. J Clin Invest 1997;99:2192-202.

46. Van den Enden MK, Nyengaard JR, Ostrow E, Burgan JH, Williamson JR. Elevated glucose levels increase retinal glycolysis and sorbitol pathway metabolism: implications for diabetic retinopathy. Invest Ophthalmol Vis Sci 1995;36:1675-85.

47. Sorbinil Retinopathy Trial Research Group. A randomised trial of sorbinil, an aldose reductase inhibitor, in diabetic retinopathy. Arch Ophthalmol 1990;108:1234-44.

48. Engerman RL, Kern TS. Aldose reductase inhibition fails to prevent retinopathy in diabetic and galactosaemic dogs. Diabetes 1993;42:820-5.

49. Vasilets LA, Schwarz W. Structure-function relationships of cation binding in the $\mathrm{Na}^{+} / \mathrm{K}^{+}$-ATPase. Biochim Biophys Acta 1993;1154:201-22.

50. Skou JC. The Na/K-pump. Methods Enzymol 1988;156:1-25.

51. Lingrel JB. $\mathrm{Na}^{+} / \mathrm{K}^{+}$-ATPase: isoform structure, function and expression. J Bioenerg Biomemb 1992;24:263-70.

52. Hawthorne GC, Barlett K, Hetherington CS, Alberti KG. The effect of high glucose on polyol pathway activity and myoinositol metabolism in cultured human endothelial cells. Diabetologia 1989;32:163-6.

53. Ottlecz A, Bensaoula T. Captopril ameliorates the decreased $\mathrm{Na}^{+} / \mathrm{K}^{+}$-ATPase activity in the retina of streptozotocininduced diabetic rats. Invest Ophthalmol Vis Sci 1996;37:1633-41.

54. Engerman RL, Kern TS, Larson ME. Nerve conduction and aldose reductase inhibition during 5 years of diabetes or galactosaemia in dogs. Diabetologia 1994;37:141-4.

55. Pfeifer MA, Schumer MP, Gelber DA. Aldose reductase inhibitors: the end of an era or the need for different trial designs? Diabetes 1997;46:S82-9.

56. King GL, Ishii H, Koya D. Diabetic vascular dysfunctions: a model of excessive activation of protein kinase C. Kidney Int 1997;60:S77-85.

57. Shiba T, Inoguchi T, Sportman JR, Heath W, Bursell S, King GL. Correlation of diacylglycerol and protein kinase C activity in rat retina to retinal circulation. Am J Physiol 1993;265:E783-93.

58. Kikkawa $U$, Nishizuka Y. The role of protein kinase $C$ in transmembrane signalling. Annu Rev Cell Biol 1986;2:149-78.

59. King GL, Shiba T, Oliver J, Inoguchi T, Bursell S-E. Cellular and molecular. abnormalities in the vascular endothelium of diabetes mellitus. Annu Rev Med 1994;45:179-88.

60. Ishii H, Jirousék MR, Koya D, Takagi C, Xia P, Clermont A, et al. Amelioration of vascular dysfunction in diabetic rats by an oral PKC beta inhibitor. Science 1996;272:728-31. 
61. Bursell S-E, Takagi C, Clermont AC, Takagi H, Mori F, Ishii $\mathrm{H}$, et al. Specific retinal diacylglycerol and protein kinase $\mathrm{C}$ beta-isoform modulation mimics abnormal retinal hemodynamics in diabetic rats. Invest Ophthalmol Vis Sci 1997;38:2711-20.

62. Baynes JW. Role of oxidative stress in development of complications in diabetes. Diabetes 1991;40:405-12.

63. Giugliano D, Ceriello A, Paolisso G. Oxidative stress and diabetic vascular complications. Diabetes Care 1996;19:257-67.

64. Asahina T, Kashiwagi A, Nishio Y, Ikebuchi M, Harada N, Tanaka $Y$, et al. Impaired activation of glucose oxidation and NADPH supply in human endothelial cells exposed to $\mathrm{H}_{2} \mathrm{O}_{2}$ in high glucose medium. Diabetes 1995;44:520-6.

65. Agardh CD, Agardh E, Hultberg B, Qian Y, Östenson C-G. The glutathione levels are reduced in Goto-Kakizaki rat retina, but are not influenced by aminoguanidine treatment. Curr Eye Res 1998;17:251-6.

66. Sharpe PC, Liu WH, Yue KK, McMaster D, Catherwood MA, McGinty AM, et al. Glucose-induced oxidative stress in vascular contractile cells: comparison of aortic smooth muscle cells and retinal pericytes. Diabetes 1998;47:801-9.

67. Wells-Knecht MC, Lyons TJ, McCance DR, Thorpe SR, Baynes JW. Age-dependent increase in ortho-tyrosine and methionine sulfoxide in human skin collagen is not accelerated in diabetes: evidence against a generalised increase in oxidative stress in diabetes. J Clin Invest 1997;100:839-46.

68. Li W, Liu X, He Z, Yanoff M, Jian BO, Ye X. Expression of apoptosis regulatory genes by retinal pericytes after rapid glucose reduction. Invest Ophthalmol Vis Sci 1998;39:1535-43.

69. Lyons TJ, Li W, Wells-Knecht MC, Jokl R. Toxicity of mildly modified low-density lipoproteins to cultured retinal capillary endothelial cells and pericytes. Diabetes 1994;43:1090-5.

70. Kowluru RA, Kern TS, Engerman RL, Armstrong D. Abnormalities of retinal metabolism in diabetes or experimental galactosemia. III. Effects of antioxidants. Diabetes 1996;45:1233-7.

71. Mayer-Davis EJ, Bell RA, Reboussin BA, Rushing J, Stat M, Marshall JA, et al. Antioxidant nutrient intake and diabetic retinopathy. The San Luis Valley Diabetes Study. Ophthalmology 1998;105:2264-70.

72. Makita Z, Radoff S, Rayfield EJ, Yang Z, Skolnik E, Delaney $V$, et al. Advanced glycosylation end-products in patients with diabetic nephropathy. N Engl J Med 1991;325:836-42.

73. Lyons TJ. Glycation, oxidation and glycoxidation reactions in the development of diabetic complications. Contrib Nephrol 1995;112:1-10.

74. Brownlee M, Cerami A, Vlassara H. Advanced glycosylation end products in tissue and the biochemical basis of diabetic complications. $\mathrm{N}$ Engl J Med 1988;318:1315-21.

75. Lubec G, Pollak A. Reduced susceptibility of nonenzymatically glucosylated glomerular basement membrane to proteases: is thickening of diabetic glomerular basement membranes due to reduced proteolytic degradation? Renal Physiol 1980;3:4-8.

76. Merimee TJ. Diabetic retinopathy: a synthesis of perspectives. N Engl J Med 1990;322:978-83.

77. Brownlee M. Glycation products and the pathogenesis of diabetic complications. Diabetes Care 1992;15:1835-43.

78. Vlassara H, Bucala R, Striker L. Pathogenic effects of advanced glycosylation: biochemical, biologic and clinical implications for diabetes and aging. Lab Invest 1994;70:138-51.

79. Stitt AW, He C, Vlassara H. Characterisation of the advanced glycation end-product receptor complex in human vascular endothelial cells. Biochem Biophys Res Commun 1999;256:549-56.
80. Stitt AW, Li YM, Gardiner TA, Bucala R, Archer DB, Vlassara $\mathrm{H}$. Advanced glycation end-products (AGEs) colocalise with AGE receptors in the retinal vasculature of diabetic and of AGE-infused rats. Am J Pathol 1997;150:523-31.

81. Lorenzi M, Montisano DF, Toledo S, Barrieux A. High glucose induces DNA damage in cultured human endothelial cells. J Clin Invest 1986;77:322-5.

82. Bucala R, Tracey KJ, Cerami A. Advanced glycosylation products quench nitric oxide and mediate defective endothelium-dependent vasodilatation in experimental diabetes. J Clin Invest 1991;87:432-8.

83. Chakravarthy U, Hayes RG, Stitt AW, McAuley E, Archer DB. Constitutive nitric oxide synthase expression in retinal vascular endothelial cells is suppressed by high glucose and advanced glycation end-products. Diabetes 1998;47:945-52.

84. Cerami C, Founds H, Nicholl I, Mitsuhashi T, Giordano D, Van Patten $\mathrm{S}$, et al. Tobacco smoke is a source of toxic reactive glycation products. Proc Natl Acad Sci USA 1997;94:13915-20.

85. Nicholl ID, Stitt AW, Moore JE, Ritchie AJ, Archer DB, Bucala R. Increased levels of advanced glycation endproducts in the lenses and blood vessels of cigarette smokers. Mol Med 1998;4:594-601.

86. Moss SE, Klein R, Klein BE. The 14-year incidence of visual loss in a diabetic population. Ophthalmology 1998;105:998-1003.

87. Moss SE, Klein R, Klein BE. Cigarette smoking and ten-year progression of diabetic retinopathy. Ophthalmology 1996;103:1438-42.

88. Linsenmeier RA, Braun RD, McRipley MA, Padnick LB, Ahmed J, Hatchell DL, et al. Retinal hypoxia in long-term diabetic cats. Invest Ophthalmol Vis Sci 1998;39:1647-57.

89. Pe'er J, Shweiki D, Itin A, Hemo I, Gnessin H, Keshet E. Hypoxia-induced expression of vascular endothelial growth factor by retinal cells is a common factor in neovascularising ocular diseases. Lab Invest 1995;72:638-45.

90. Takagi H, King GL, Robinson GS, Ferrara N, Aiello LP. Adenosine mediates hypoxic induction of vascular endothelial growth factor in retinal pericytes and endothelial cells. Invest Ophthalmol Vis Sci 1996;37:2165-76.

91. Miller JW, Adamis AP, Shima DT, D'Amore PA, Moulton RS, O'Reilly MS, et al. Vascular endothelial growth factor/ vascular permeability factor is temporally and spatially correlated with ocular angiogenesis in a primate model. Am J Pathol 1994;145:574-84.

92. Shweiki D, Itin A, Soffer D, Keshet E. Vascular endothelial growth factor induced by hypoxia may mediate hypoxiainitiated angiogenesis. Nature 1992;359:843-5.

93. Caprioli J, Kitano S, Morgan JE. Hyperthermia and hypoxia increase tolerance of retinal ganglion cells to anoxia and excitotoxicity. Invest Ophthalmol Vis Sci 1996;37:2376-81.

94. Feke GT, Buzney SM, Ogasawara H, Fujio N, Goger DG, Spack NP, et al. Retinal circulatory abnormalities in type 1 diabetes. Invest Ophthalmol Vis Sci 1994;35:2968-75.

95. Schröder S, Palinski W, Schmid-Schönbein GW. Activated monocytes and granulocytes, capillary non-perfusion and neovascularisation in diabetic retinopathy. Am J Pathol 1991;139:81-100.

96. Miyamoto K, Ogura Y, Kenmochi S, Honda Y. Role of leukocytes in diabetic microcirculatory disturbances. Microvasc Res 1997;54:43-8.

97. Miyamoto K, Hiroshiba N, Tsujikawa A, Ogura Y. In vivo demonstration of increased leucocyte entrapment in retinal microcirculation of diabetic rats. Invest Ophthalmol Vis Sci 1998;39:2190-4.

98. Hatchell DL, Wilson CA, Saloupis P. Neutrophils plug capillaries in acute experimental ischemia. Microvasc Res 1994;47:344-54 
99. Braun RD, Fisher TC, Meiselman HJ, Hatchell DL. Decreased deformability of polymorphonuclear leukocytes in diabetic cats. Microcirculation 1996;3:271-8.

100. Anderson HR, Stitt AW, Gardiner TA, Archer DB. Stereological estimation of Weibel-Palade bodies in the retinal vasculature of normal and diabetic dogs. Curr Eye Res 1994;13:705-10.

101. Vracko R, Benditt EP. Manifestations of diabetes mellitus: their possible relationships to an underlying cell defect [review]. Am J Pathol 1974;75:204-24.

102. Mizutani M, Kern TS, Lorenzi M. Accelerated death of retinal microvascular cells in human and experimental diabetic retinopathy. J Clin Invest 1996;97:2883-90.

103. Kerr JFR, Wyllie AH, Currie AR. Apoptosis: a basic biological phenomenon with wide-ranging implications in tissue kinetics. Br J Cancer 1972;26:239-57.

104. Nickells RW, Zack DJ. Apoptosis in ocular disease: a molecular overview. Ophthalmic Genet 1996;17:145-65.

105. Green D, Kroemer G. The central executioners of apoptosis: caspases or mitochondria? Trends Cell Biol 1998;8:267-71.

106. Polyak K, Xia Y, Zweier JL, Kinzler KW, Vogelstein B. A model for p53-induced apoptosis. Nature 1997;389:300-5.

107. Grunwald JE, Riva CE, Brucker AJ, Sinclair SH, Petrig BL. Altered retinal vascular response to $100 \%$ oxygen breathing in diabetes mellitus. Ophthalmology 1984;91:1447-52.

108. Sinclair SH, Grunwald JE, Riva CE, Braunstein SN, Nichols $\mathrm{CW}$, Schwartz SS. Retinal vascular autoregulation in diabetes mellitus. Ophthalmology 1982;89:748-50.

109. Fallon TJ, Maxwell DL, Köhner EM. Autoregulation of retinal blood flow in diabetic retinopathy measured by the blue light entopic technique. Ophthalmology 1987;94:1410-5.

110. Patel V, Rassam SMB, Chen HC, Köhner EM. Oxygen reactivity in diabetes mellitus: effect of hypertension and hyperglycaemia. Clin Sci 1994;86:689-95.

111. Takagi C, King GL, Clermont AC, Cummins DR, Takagi $\mathrm{H}$, Bursell S-V. Reversal of abnormal retinal hemodynamics in diabetic rats by acarbose, an alpha-glucosidase inhibitor. Curr Eye Res 1995;14:741-9.

112. Bursell S-E, Clermont AC, Kinsley BT, Simonson DC, Aiello LM, Wolpert HA. Retinal blood flow changes in patients with insulin-dependent diabetes mellitus and no diabetic retinopathy. Invest Ophthalmol Vis Sci 1996;37:886-97.

113. Grunwald JE, Riva CE, Martin DB, Quint AR, Epstein PA. Effect of an insulin-induced decrease in blood glucose on the human diabetic retinal circulation. Ophthalmology 1987;94:1614-20

114. Tiedeman JS, Kirk SE, Srinivas S, Beach JM. Retinal oxygen consumption during hyperglycaemia in patients with diabetes without retinopathy. Ophthalmology 1998;105:31-6.

115. Grunwald JE, Brucker AJ, Schwartz SS, Braunstein SN, Baker L, Petrig BL, et al. Diabetic glycemic control and retinal blood flow. Diabetes 1990;39:602-7.

116. Grunwald JE, Riva CE, Sinclair SH, Brucker AJ, Petrig BL. Laser doppler velocimetry study of retinal circulation in diabetes mellitus. Arch Ophthalmol 1986;104:991-6.

117. Patel V, Rassam S, Newsom R, Wiek J, Köhner E. Retinal blood flow in diabetic retinopathy. BMJ 1993;305:678-83.

118. Grunwald JE, Brucker AJ, Grunwald SE, Riva CE. Retinal hemodynamics in proliferative diabetic retinopathy: a laser doppler velocimetry study. Invest Ophthalmol Vis Sci 1993;34:66-71.

119. Chakravarthy U, Gardiner TA, Anderson P, Archer DB Trimble ER. The effect of endothelin-1 on the retinal microvascular pericyte. Microvasc Res 1992;43:241-54.

120. Chakravarthy U, McGinty A, McKillop J, Anderson P, Archer DB, Trimble ER. Altered endothelin-1 contraction and second messenger generation in bovine retinal microvascular pericytes cultured in high glucose medium. Diabetologia 1994;37:36-42.
121. Bursell S-V, Clermont AC, Oren B, King GL. The in vivo effect of endothelins on retinal circulation in non-diabetic and diabetic rats. Invest Ophthalmol Vis Sci 1995;36:596-607.

122. Donati G, Pournaras CJ, Munoz J-L, Poitry S, Poitry-Yamate $\mathrm{CL}$, Tsacopoulos M. Nitric oxide controls arteriolar tone in the retina of the miniature pig. Invest Ophthalmol Vis Sci 1995;36:2228-37.

123. Takagi C, Bursell S-E, Lin Y-W, Takagi H, Duh E, Jiang Z, et al. Regulation of retinal hemodynamics in diabetic rats by increased expression and action of endothelin-1. Invest Ophthalmol Vis Sci 1996;37:2504-18.

124. Chakrabarti S, Gan XT, Merry A, Karmazyn M, Sima AAF. Augmented retinal endothelin- 1 , endothelin-3, endothelin- $\alpha$, endothelin- $\beta$ gene expression in chronic diabetes. Curr Eye Res 1998;17:301-7.

125. Howard M, Sen HA, Capoor S, Herfel R, Crooks PA, Jacobson MK. Measurement of adenosine concentration in aqueous and vitreous. Invest Ophthalmol Vis Sci 1998:39:1942-6.

126. Matsugi T, Chen Q, Anderson DR. Adenosine-induced relaxation of cultured bovine retinal pericytes. Invest Ophthalmol Vis Sci 1997;38:2695-701.

127. Gillies MC, Su T. High glucose inhibits retinal capillary pericyte contractility in vitro. Invest Ophthalmol Vis Sci 1993;34:3396-401.

128. Chakrabarti S, Sima AAF. Endothelin-1 and endothelin-3 like immunoreactivity in the eyes of diabetic and nondiabetic BB/W rats. Diabetes Res Clin Pract 1997;37:109-20.

129. De La Rubia G, Oliver FJ, Inoguchi T, King GL. Induction of resistance to endothelin-1's biochemical actions by elevated glucose levels in retinal pericytes. Diabetes 1992;41:1533-9.

130. Rao KM, Hatchell DL, Cohen HJ, De La Paz MA. Alterations in stimulus-induced integrin expression in peripheral blood neutrophils of patients with diabetic retinopathy. Am J Sci 1997;313:131-7.

131. Weinberger D, Fink-Cohen S, Gaton DD, Priel E, Yassur Y. Non-retinovascular leakage in diabetic maculopathy. $\mathrm{Br} \mathrm{J}$ Ophthalmol 1995;79:728-31.

132. Cunha-Vaz JG, Gray JR, Zeimer RC, Moto MC, Ishimoto $\mathrm{BM}$, Leite E. Characterisation of the early stages of diabetic retinopathy by vitreous fluorophotometry. Diabetes 1985;34:53-9.

133. Gillies MC, Su T, Stayt J, Simpson JM, Naidoo D, Salonikas C. Effect of high glucose on permeability of retinal capillary endothelium in vitro. Invest Ophthalmol Vis Sci 1997;38:635-42.

134. Antonetti DA, Barber AJ, Khin S, Leith E, Tarbell JM, Gardner TW. Vascular permeability in experimental diabetes is associated with reduced endothelial occludin content: vascular endothelial growth factor decreases occludin in retinal endothelial cells. Diabetes 1998;47:1953-9.

135. Vinores SA, Van Niel E, Swerdloff JL, Campochiaro PA. Electron microscopic immunocytochemical demonstration of blood-retinal barrier breakdown in human diabetics and its association with aldose reductase in retinal vascular endothelium and retinal pigment epithelium. Histochem J 1993;25:648-63.

136. Ishibashi $\mathrm{T}$, Inomata $\mathrm{H}$. Ultrastructure of retinal vessels in diabetic patients. Br J Ophthalmol 1993;77:574-8.

137. Fry DL. Certain histological and chemical responses of the vascular interface to acutely induced mechanical stress in the aorta of the dog. Circ Res 1969;24:93-108.

138. McMillan DE. The effect of diabetes on blood flow properties. Diabetes 1983;32:56-63.

139. Davies PF, Dewey CF Jr, Bussolari SR, Gordon EJ, Gimbrone MA Jr. Influence of hemodynamic forces on vascular endothelial function: in vitro studies of shear stress and pinocytosis in bovine aortic cells. J Clin Invest 1984:73:1121-9. 
140. Danis RP, Bingaman DP. Insulin-like growth factor-1 retinal microangiography in the pig eye. Ophthalmology 1997;104:1661-9.

141. Stitt AW, Simpson DAC, Boocock C, Gardiner TA, Murphy GM, Archer DB. Expression of vascular endothelial growth factor (VEGF) and its receptors is regulated in eyes with intraocular tumours. J Pathol 1998;186:306-12.

142. Colville-Nash PR, Willoughby DA. Growth factors in angiogenesis: current interest and therapeutic potential [review]. Mol Med Today 1997;3:14-23.

143. Mathews MK, Merges C, McLeod DS, Lutty GA. Vascular endothelial growth factor and vascular permeability changes in human diabetic retinopathy. Invest Ophthalmol Vis Sci 1997;38:2729-41.

144. Miller JW, Adamis AP, Aiello LP. Vascular endothelial growth factor in ocular neovascularisation and proliferative diabetic retinopathy. Diabetes Metab Rev 1997;13:37-50.

145. Tolentino M, Miller JW, Gragoudas ES, Jakobiec FA, Flynn $\mathrm{E}$, Chatzistefanou $\mathrm{K}$, et al. Intravitreous injections of vascular endothelial growth factor produce retinal ischemia and microangiopathy in an adult primate. Ophthalmology 1996;103:1820-8.

146. Stone J, Itin A, Alon T, Pe'er J, Gnessin H, Chang-Ling T, et al. Development of retinal vasculature is mediated by hypoxia-induced vascular endothelial growth factor (VEGF) expression by neuroglia. J Neurosci 1995;15:4738-47.

147. Aiello LP. Vascular endothelial growth factor: 20th century mechanisms, 21st century therapies. Invest Ophthalmol 1997;38:1647-52.

148. Williams B, Gallagher B, Patel H, Orme C. Glucose-induced protein kinase $C$ activation regulates vascular permeability factor mRNA expression and peptide production by human vascular smooth muscle cells in vitro. Diabetes 1997;46:1497-503.

149. Pe'er J, Folberg R, Itin A, Gnessin H, Hemo I, Keshet E. Vascular endothelial growth factor up-regulation in human central retinal vein occlusion. Ophthalmology 1998;105:412-6.

150. Dvorak HF, Brown LF, Detmar M, Dvorak AM. Vascular permeability factor/vascular endothelial growth factor, microvascular hyperpermeability and angiogenesis. Am J Pathol 1995;146:1029-39.

151. Pournaras CJ, Miller JW, Gragoudas ES, Husain D, Munoz $\mathrm{JL}$, Tolentino MJ, et al. Systemic hyperoxia decreases vascular endothelial growth factor gene expression in ischemic primate retina. Arch Ophthalmol 1997;115:1553-8.

152. Alon T, Hemo I, Itin A, Pe'er J, Stone J, Keshet E. Vascular endothelial growth factor acts as a survival factor for newly formed retinal vessels and has implications for retinopathy of prematurity. Nature Med 1995;1:1024-8.

153. Murata T, Ishibashi T, Khalil A, Hata $Y$, Yoshikawa $H$ Inomata $\mathrm{H}$. Vascular endothelial growth factor plays a role in hyperpermeability of diabetic retinal vessels. Ophthalmic Res 1995;27:48-52.

154. Roberts WG, Palade GE. Increased microvascular permeability and endothelial fenestration induced by vascular endothelial growth factor. J Cell Sci 1995;108:2369-79.

155. Adamis AP, Miller JW, Bernal M-T, D'Amico DJ, Folkman J, Yeo TK, et al. Increased vascular endothelial growth factor levels in the vitreous of eyes with proliferative diabetic retinopathy. Am J Ophthalmol 1994;118:445-50.

156. Aiello LP, Avery RL, Arrig PG, Keyt BA, Jampel HD, Shah ST, et al. Vascular endothelial growth factor in ocular fluid of patients with diabetic retinopathy and other retinal disorders. N Engl J Med 1994;331:1480-7.

157. Stitt AW, Anderson HR, Gardiner TA, McIntyre I, Archer DB. The combined effects of diabetes and ionizing radiation on the rat retina: an ultrastructural study. Curr Eye Res 1994;13:79-86.
158. Gardner TW. Histamine, ZO-1 and increased blood-retinal barrier permeability in diabetic retinopathy. Trans Am Ophthalmol Soc 1995;93:583-621.

159. Gardiner TA, Stitt AW, Archer DB. Retinal vascular endothelial cell endocytosis increases in early diabetes. Lab Invest 1995;72:439-44.

160. Stitt AW, Chakravarthy U, Archer DB, Gardiner TA. Increased endocytosis in retinal vascular endothelial cells grown in high glucose medium is modulated by inhibitors of non-enzymatic glycosylation. Diabetologia 1995;38:1271-5.

161. Archer DB, Amoaku WMK, Gardiner TA. Radiation retinopathy: clinical, histopathological, ultrastructural and experimental correlations. Eye 1991;5:239-51.

162. Kumagai AK, Glasgow BJ, Pardridge WM. Glut 1 glucose transporter expression in the diabetic and non-diabetic human eye. Invest Ophthalmol Vis Sci 1994;35:2887-94.

163. Engerman RL, Kern TS. Retinopathy in animal models of diabetes. Diabet Metabol Rev 1995;11:109-20.

164. Stitt AW, Anderson HR, Gardiner TA, Archer DB. Diabetic retinopathy: quantitative variation in capillary basement membrane thickening in arterial or venous environments. Br J Ophthalmol 1994;78:133-7.

165. Gardiner TA, Archer DB. Fine structural changes in retinal vessels of experimental and spontaneously diabetic dogs. Doc Ophthalmol 1990;76:171.

166. Roy S, Maiello M, Lorenzi M. Increased expression of basement membrane collagen in human diabetic retinopathy. J Clin Invest 1994;93:438-42.

167. Roy S, Cagliero E, Lorenzi M. Fibronectin overexpression in retinal microvessels of patients with diabetes. Invest Ophthalmol Vis Sci 1996;37:258-66.

168. Cagliero E, Maiello M, Boedri D, Roy S, Lorenzi M. Increased expression of basement membrane components in human endothelial cells cultured in high glucose. J Clin Invest 1988;82:735-8.

169. Robison WG, Jacot JL, Glover JP, Basso MD, Hohman TC. Diabetic-like retinopathy: early and late intervention therapies in galactose-fed rats. Invest Ophthalmol Vis Sci 1988;39:1933-41.

170. Cogan DG, Toussaint D, Kuwabara T. Retinal vascular patterns. IV. Diabetic retinopathy. Arch Ophthalmol 1961;66:366-78

171. Kuwabara T, Cogan DG. Retinal vascular patterns. VI. Mural cells of the retinal capillaries. Arch Ophthalmol 1963;69:492-502.

172. Chibber R, Molinatti PA, Rosatto N, Lambourne B, Köhner EM. Toxic action of advanced glycation end-products on cultured retinal capillary pericytes and endothelial cells: relevance to diabetic retinopathy. Diabetologia 1997;40:156-64.

173. Hammes HP, Martin S, Federlin K, Geisen K, Brownlee H. Aminoguanidine treatment inhibits the development of experimental diabetic retinopathy. Proc Natl Acad Sci USA 1991;88:11555-8.

174. Stitt AW, Gardiner TA, Archer DB. Histological and ultrastructural investigation of retinal microaneurysm development in diabetic patients. Br J Ophthalmol 1995;79:362-7.

175. Arend O, Wolf S, Jung F, Bertram B, Pöstgens $\mathrm{H}$, Toonen $\mathrm{H}$ et al. Retinal microcirculation in patients with diabetes mellitus: dynamic and morphological analysis of perifoveal capillary network. Br J Ophthalmol 1991;75:514-8.

176. D'Amore PA. Mechanisms of retinal and choroidal neovascularisation. Invest Ophthalmol Vis Sci 1994;35:3974-9.

177. Sebag J, Buckingham B, Charles MA, Reiser K. Biochemical abnormalities in vitreous of humans with proliferative diabetic retinopathy. Arch Ophthalmol 1992;110:1472-6. 
178. Stitt AW, Moore JE, Sharkey JA, Murphy G, Simpson DAC, Bucala $R$, et al. Advanced glycation end-products in vitreous: structural and functional implications for diabetic vitreopathy. Invest Ophthalmol Vis Sci 1998;39:2517-23.

179. Stitt AW, McKenna D, Simpson DAC, Gardiner TA Harriott $P$, Archer DB, et al. The 67-kd laminin receptor is preferentially expressed by proliferating retinal vessels in a murine model of ischemic retinopathy. Am J Pathol 1998;152:1359-65.

180. Hammes HP, Brownlee M, Jonczyk A, Sutter A, Preissner KT. Subcutaneous injection of a cyclic peptide antagonist of vitronectin receptor-type integrins inhibits retinal neovascularisation. Nature Med 1996;2:529-33.

181. Friedlander M, Theesfeld CL, Sugita M, Fruttiger M, Thomas MA, Chang S, et al. Involvement of integrins alphav-beta 3 and alpha-v-beta 5 in ocular neovascular diseases. Proc Natl Acad Sci USA 1996;93:9764-9.

182. Leung DW, Cachianes G, Kaung WJ, Goeddel DV, Ferrara $\mathrm{N}$. Vascular endothelial growth factor is a secreted angiogenic mitogen. Science 1989;246:1306-9.

183. Aiello LP. Vascular endothelial growth factor and the eye: biochemical mechanisms of action and implications for novel therapies. Ophthalmic Res 1997;29:354-62.

184. Tripathi RC, Li J, Tripathi BJ, Chalam KV, Adamis AP. Increased level of vascular endothelial growth factor in aqueous humor of patients with neovascular glaucoma. Ophthalmology 1998;105:232-7.

185. Schweigerer L, Neufeld G, Friedman J, Abraham JA, Fiddes JC, Gospodarowicz D. Capillary endothelial cells express basic fibroblast growth factor, a mitogen that promotes their own growth. Nature 1987;325:257-9.

186. Glaser BM. Extracellular modulating factors and the control of intraocular neovascularisation: an overview. Arch Ophthalmol 1998;106:603-7.

187. Sivalingam A, Kenney J, Brown GC, Benson WE, Donoso L. Basic fibroblast growth factor levels in the vitreous of patients with proliferative diabetic retinopathy. Arch Ophthalmol 1990;108:869-72.

188. Meyer-Schwickerath R, Pfeiffer A, Blum WF, Freyberger $H$, Klein M, Losche C, et al. Vitreous levels of the insulin-like growth factors I and II, and the insulin-like growth factor binding proteins 2 and 3 , increase in neovascular eye diseases: studies in non-diabetic and diabetic subjects. J Clin Invest 1993;92:2620-5.

189. Connor TB Jr, Roberts AB, Sporn MB, Danielpour D, Dart LL, Michels RG, et al. Correlation of fibrosis and transforming growth factor-beta type 2 levels in the eye. J Clin Invest 1989;83:1661-6.

190. Boulton M, Gregor Z, McLeod D, Charteris D, Jarvis-Evans $\mathrm{J}$, Moriarty $\mathrm{P}$, et al. Intravitreal growth factors in proliferative diabetic retinopathy: correlation with neovascular activity and glycaemic management. Br J Ophthalmol 1997;81:228-33.

191. Mitchell P, Smith W, Chey T, WangJJ, Chang A. Prevalence and associations of epiretinal membranes. The Blue Mountains Eye Study, Australia. Ophthalmology 1997;104:1033-40.

192. Keller RJ, Eisenbarth GA, Jackson RA. Insulin prophylaxis in individuals at high risk of type I diabetes. Lancet 1993;341:927-8.

193. Elliott RB, Chase HP. Prevention or delay of type 1 (insulindependent) diabetes mellitus in children using nicotinamide. Diabetologia 1991;34:362-5.

194. Jackson RA, Vardi T, Herskowitz RD, Soeldner JS, Eisenbarth GS. Dual parameter linear model for prediction of type 1 diabetes in islet cell antibody positive relatives. Clin Res 1988;36:484a.

195. Sutherland DER. Pancreatic transplantation. Diabetes Rev 1993;1:152-65.
196. Robertson RP. Pancreatic and islet transplantation for diabetes: cures or curiosities? Seminars in medicine of the Beth Israel Hospital, Boston. N Engl J Med 1992;327:1861-8.

197. Ramsay RC, Goetz FC, Sutherland DE, Mauer SM, Robison LL, Cantrill HL, et al. Progression of diabetic retinopathy after pancreas transplantation for insulin-dependent diabetes mellitus. N Engl J Med 1988;318:208-14.

198. Petersen MR, Vine AK. University of Michigan Pancreas Transplant Evaluation Committee. Progression of diabetic retinopathy after pancreas transplantation. Ophthalmology 1990;97:496-502.

199. Robertson RP. Pancreas transplantation in humans with diabetes mellitus. Diabetes 1991;40:1085-9.

200. Federlin K, Bretzel RG, Hering BJ. Recent achievements in experimental and clinical islet transplantation. Diabetic Med 1991;8:5-12.

201. United Kingdom Prospective Diabetes Study (UKPDS) Group. UK Prospective Diabetes Study 33. Intensive blood glucose control with sulphonylureas or insulin compared with conventional treatment and risk of complications in patients with type 2 diabetes. Lancet 1998;352:837-53.

202. O'Rahilly S. Science, medicine and the future. Non-insulin dependent diabetes mellitus: the gathering storm. BMJ 1997;314:955-9.

203. The Diabetes Control and Complications Trial Research Group. Hypoglycemia in the Diabetes Control and Complications Trial. Diabetes 1997;46:271-86.

204. Engerman RL, Kern TS. Progression of incipient diabetic retinopathy during good glycemic control. Diabetes 1987;36:808-12.

205. Engerman RL, Kern TS. Retinopathy in galactosemic dogs continues to progress after cessation of galactosemia. Arch Ophthalmol 1995;113:355-8.

206. Robison WG Jr, Laver NM, Lou MF. The role of aldose reductase in diabetic retinopathy: prevention and intervention studies. Prog Retinal Eye Res 1995;14:593-640.

207. Gazis A, Page S, Cockcroft J. Vitamin E and cardiovascular protection in diabetes. BMJ 1997;314:1845-6.

208. Kunisaki M, Bursell S-E, Umeda F, Nawata H, King GL. Normalisation of diacylglycerol-protein kinase $\mathrm{C}$ activation by vitamin $\mathrm{E}$ in aorta of diabetic rats and cultured rat smooth muscle cells exposed to elevated glucose levels. Diabetes 1994;43:1372-7.

209. Kunisaki M, Bursell S-E, Clermont AC, Ishii H, Ballas LM, Jirousek MR, et al. Vitamin E prevents diabetes-induced abnormal retinal blood flow via the diacylglycerol-protein kinase C pathway. Am J Physiol 1995;269:E239-46.

210. Robison WG Jr, Laver NM, Jacot JL, Glover JP, Basso MD, Blouin $\mathrm{P}$, et al. Diabetic-like retinopathy ameliorated with the aldose reductase inhibitor WAY-121,509. Invest Ophthalmol Vis Sci 1996;37:1149-56.

211. Frank RN, Amin R, Kennedy A, Hohman TC. An aldose reductase inhibitor and aminoguanidine prevent vascular endothelial growth factor expression in rats with long-term galactosemia. Arch Ophthalmol 1997;115:1036-47.

212. Cunha-Vaz JG, Mota CC, Leite EC, Abreu JR, Ruas MA. Effect of sorbinil on blood-retinal barrier in early diabetic retinopathy. Diabetes 1989;35:574-8.

213. Frank RN. Diabetic retinopathy. Prog Retinal Eye Res 1995;14:361-92.

214. Danis RP, Bingaman DP, Jirousek M, Yang Y. Inhibition of intraocular neovascularisation caused by retinal ischemia in pigs by PKC $\beta$ inhibition with LY333531. Invest Ophthalmol Vis Sci 1998;39:171-9.

215. Brownlee M, Vlassara H, Kooney A, Ulrich P, Cerami A. Aminoguanidine prevents diabetes-induced arterial wall protein cross-linking. Science 1986;232:1629-32.

216. Vasan S, Zhang X, Zhang X, Kapurniotu A, Bernhagen J, Teichberg S, et 'al. An agent cleaving glucose-derived protein crosslinks in vitro and in vivo. Nature 1996;382:275-8. 
217. Tilton RG, Chang K, Hasan KS, Smith SR, Petrash JM, Misko $T P$, et al. Prevention of diabetic vascular dysfunction by guanidines: inhibition of nitric oxide synthase versus advanced glycation end-product formation. Diabetes 1993;42:221-32.

218. Larsen M, Hommel E, Parving H-H, Lund-Andersen $\mathrm{H}$. Protective effect of captopril on the blood-retinal barrier in normotensive insulin-dependent diabetic patients with nephropathy and background retinopathy. Graefes Arch Clin Exp Ophthalmol 1990;228:505-9.

219. Ottlecz A, Garcia CA, Elchberg J, Fox DA. Alterations in retinal $\mathrm{Na}^{+} / \mathrm{K}^{+}$-ATPase in diabetes: streptozotocin-induced and Zucker diabetic fatty rats. Curr Eye Res 1993;12:1111-21.

220. Gupta S, Suiman I, McArthur CS, Tornheim K, Cohen RA, Ruerman NB. Endothelium-dependent inhibition of $\mathrm{Na}^{+} /$ $\mathrm{K}^{+}$-ATPase activity in rabbit aorta in hyperglycemia: possible role of endothelium-derived nitric oxide. J Clin Invest 1992;90:727-32

221. Gin T, Joon TL, Panagiotopoulos S, Cooper M, Taylor H, Jerums G. Organ specificity of antihypertensive therapy on ocular vascular clearance and albuminuria in the hypertensive diabetic rat. Invest Ophthalmol Vis Sci 1996;37:281-9.

222. Early Treatment Diabetic Retinopathy Study Research Group. Effects of aspirin treatment on diabetic retinopathy. ETDRS report no. 8. Ophthalmology 1991;98:757-65.

223. Gardner TW, Eller AW, Friberg TR, D'Antonio JA, Hollis TM. Antihistamines reduce blood-retinal barrier permeability in type-1 (insulin-dependent) diabetic patients with non-proliferative retinopathy: a pilot study. Retina 1995;15:134-40.

224. Aiello LP, Bursell SE, Clermont A, Duh E, Ishii H, Takagi C, et al. Vascular endothelial growth factor-induced retinal permeability is mediated by protein kinase $C$ in vivo and suppressed by an orally effective beta-isoform-selective inhibitor. Diabetes 1997:46:1473-80.
225. Rubsamen PE, Davis PA, Hernandez E, O'Grady GE, Cousins SW. Prevention of experimental proliferative vitreoretinopathy with a biodegradable intravitreal implant for the sustained release of fluorouracil. Arch Ophthalmol 1994;112:407-13.

226. Yang C-S, Khawly JA, Hainsworth DP, Chen S-N, Ashton P, Guo $\mathrm{H}$, et al. An intravitreal sustained-release triamcinolone and 5-fluorouracil co-drug in the treatment of experimental proliferative vitreoretinopathy. Arch Ophthalmol 1998;116:69-77.

227. Siliprandi R, Canella R, Carmignoto G. Nerve growth factor promotes functional recovery of retinal ganglion cells after ischemia. Invest Ophthalmol Vis Sci 1993;34:3232-45.

228. Schumacher B, Pecher P, von Specht BU, Stegmann T. Induction of neoangiogenesis in ischemic myocardium by human growth factors: first clinical results of a new treatment of coronary heart disease. Circulation 1998;97:645-50.

229. Adamis AP, Shima DT, Tolentino MJ, Gragoudas ES, Ferrara N, Folkman J, et al. Inhibition of vascular endothelial growth factor prevents ischemia-associated iris neovascularisation in a non-human primate. Arch Ophthalmol 1996;114:66-71.

230. Aiello LP, Pierce EA, Foley ED, Takagi H, Chen H, Riddle L, et al. Suppression of retinal neovascularisation in vivo by inhibition of vascular endothelial growth factor (VEGF) using soluble VEGF receptor chimeric proteins. Proc Natl Acad Sci USA 1995;92:10457-61.

231. Robinson GF, Pierce EA, Rook SL, Foley E, Webb R, Smith LE. Oligodeoxynucleotides inhibit retinal neovascularisation in a murine model of proliferative retinopathy. Proc Natl Acad Sci USA 1996;93:4851-6.

232. Goto F, Goto K, Weindel K, Folkman J. Synergistic effects of vascular endothelial growth factor and basic fibroblast growth factor on the proliferation and cord formation of bovine capillary endothelial cells within collagen gels. Lab Invest 1993;69:508-17.

233. Sebag J. Pharmacologic vitreolysis. Retina 1998;18:1-3. 